\begin{tabular}{ccc|} 
ISSN = 1980-993X - doi:10.4136/1980-993X \\
www.ambi-agua.net \\
E-mail: ambi-agua@agro.unitau.br \\
Tel.: (12) 3625-4212
\end{tabular}

\title{
Desenvolvimento de modelo conceitual termodinâmico para o reservatório hidrelétrico de Itumbiara baseado em dados de satélite e telemétricos
}

\author{
(http://dx.doi.org/10.4136/ambi-agua.192) \\ Enner Herenio de Alcântara, ${ }^{1}$ \\ José Luiz Stech ${ }^{1}$ \\ ${ }^{1}$ Divisão de Sensoriamento Remoto, Instituto Nacional de Pesquisas Espaciais (DSR-INPE) \\ e-mail: \{enner, stech\}@dsr.inpe.br
}

\section{RESUMO}

Sistemas aquáticos respondem continuamente às condições climáticas, as quais variam amplamente no espaço e no tempo. A resposta de cada corpo d'água às condições externas (processos hidrometeorológicos) é revelada em um primeiro momento por meio da sua estrutura térmica. A maioria dos processos químicos, físicos e biológicos em sistemas aquáticos continentais é afetada diretamente pelo regime hidrológico do corpo d'água (por exemplo: profundidade do corpo d'água) e mudanças térmicas (por exemplo: padrão de estratificação), sendo também indiretamente afetado pelas variações climáticas. Entender o sistema reservatório-clima é de fundamental importância no entendimento dos efeitos das mudanças climáticas nos processos limnológicos. Baseado nisso o objetivo geral deste trabalho é desenvolver um modelo conceitual termodinâmico para o reservatório hidrelétrico de Itumbiara, GO. A metodologia desenvolvida foi baseada na utilização de imagens de satélite de resolução moderada, as quais permitiram a estimativa do campo de temperatura de 2003 a 2008 durante o dia e durante a noite. Os resultados mostraram o potencial do uso de imagens de satélite no estudo das variações da temperatura de superfície e, principalmente, na explicação de tais variações. O uso de dados meteorológicos e de temperatura da água em vários níveis, obtidos por estações meteorológicas e boias de monitoramento automático contribuíram para o melhor entendimento dos processos físicos na camada de mistura do reservatório. Os resultados também permitiram a elaboração de modelos conceituais sobre a termodinâmica da água do reservatório de Itumbiara.

Palavras-chave: fluxo de calor; temperatura; MODIS/Terra; estratificação e mistura.

\section{Developing a thermodynamic a conceptual model for the Itumbiara hydroelectric reservoir based on satellite and telemetric data}

\begin{abstract}
Aquatic systems continually respond to climatic conditions that vary over broad scales of space and time. The response of each water body to external conditions (hydrometeorological processes) is revealed in the first place by the thermal structures present in water body. Most lacustrine chemical, physical and biological processes are affected directly by lake hydrological (e.g. lake depth) and thermal changes (e.g. seasonal stratification), and are thus, indirectly affected by climate variation. Understanding lake-climate system
\end{abstract}


ALCÂNTARA, E. H. de; STECH, J. L. Desenvolvimento de modelo conceitual termodinâmico para o reservatório hidrelétrico de Itumbiara baseado em dados de satélite e telemétricos. Ambi-Agua, Taubaté, v. 6, n. 2, p. 157-179, 2011. (doi:10.4136/ambi-agua.192)

interactions is therefore of fundamental importance to evaluate the effects of climate change on limnological processes. Based on this, the objective of this work was to develop a thermodynamic conceptual model for the Itumbiara hydroelectric reservoir (Goiás State, Brazil). The developed methodology was based on the use of satellite imagery of moderate resolution that allow the computation of the water surface temperature from 2003 to 2008 (six years) during the daytime and nighttime. The results showed the potential of the use of moderate resolution satellite data to study water surface temperature variability and to explain the main causes of this variability. The use of hydro-meteorological and bulk temperature collected by station and autonomous buoy, respectively, contributed to better understand the physical processes in the mixed depth of the reservoir. Also the results allow the elaboration of conceptual models for the thermodynamics of the Itumbiara reservoir.

Keywords: heat flux; temperature; MODIS/Terra; stratification and mixing.

\section{INTRODUÇÃO}

Um dos parâmetros considerado chave para o entendimento da dinâmica de sistemas aquáticos é a temperatura, por ser determinante na manutenção ecológica (Horne e Goldman, 1994). Tal parâmetro também exerce influência sobre reações químicas e processos biológicos e físicos na água. A variação da temperatura com a profundidade (ocorrência ou não de estratificação térmica), por exemplo, pode ser utilizada para caracterizar a estrutura das características físicas dos reservatórios.

A estratificação de um reservatório é resultado de vários processos físicos os quais distribuem calor da superfície da água para as outras camadas. Esses processos dependem não somente de variáveis meteorológicas como, vento, radiação de onda curta e longa, mas também das características biogeoquímicas do corpo d'água. Por exemplo, a penetração da radiação de onda curta na coluna d'água depende do material particulado na água. Além disso, as diferenças de temperatura entre o ar e a água controlam os fluxos de calor e umidade, que são cruciais para o entendimento do ciclo hidrológico (Linvingstone, 1999; Straile et al., 2003).

A distribuição espacial da temperatura é fundamental para a compreensão do desempenho e do funcionamento dos reservatórios (Kimmel et al., 1990). Alguns autores têm mostrado a importância da tomada d'água em reservatórios na determinação da estratificação termal (Ford, 1990; Casamitjana et al., 2003). Tomadas d'água na superfície geralmente dissipam calor, pois a camada superficial da água aquecida é diretamente removida, resultando na preservação da água mais fria e densa no hipolímnio. Por outro lado, tomadas d'água próximo ao fundo têm a tendência de reter calor, isto porque a liberação da água fria do hipolímnio resulta em uma expansão da camada do epilímnio aquecida pela radiação solar (Kennedy, 1999). A posição da tomada d'água no reservatório pode então, modificar o campo de temperatura da superfície da água.

De forma geral, a resposta térmica de um reservatório está associada às condições climáticas e meteorológicas que causam e afetam os ciclos sazonais do balanço de energia e, assim, também a temperatura da superfície da água e a estratificação térmica (Lerman e Imboden, 1995). Fundamentalmente, a temperatura e a estrutura térmica de um sistema aquático são controladas pelas radiações de ondas longas e curtas, fluxos de calor sensível e latente, e as energias associadas às entradas e saídas de radiação do sistema aquático (Henderson-Sellers, 1986).

A retenção de calor em corpos d'água está relacionada com fatores que influenciam a sua distribuição em sistemas aquáticos, tais como, o trabalho físico realizado pela energia dos 
ALCÂNTARA, E. H. de; STECH, J. L. Desenvolvimento de modelo conceitual termodinâmico para o reservatório hidrelétrico de Itumbiara baseado em dados de satélite e telemétricos. Ambi-Agua, Taubaté, v. 6, n. 2, p. 157-179, 2011. (doi:10.4136/ambi-agua.192)

ventos, as correntes e outros movimentos da água, a morfometria, perdas e ganhos de água. $\mathrm{O}$ que resulta em padrões de sucessão termal e estratificação que influenciam de forma fundamental os ciclos biogeoquímicos, os quais governam por sua vez a produção e a decomposição em sistemas aquáticos (Chapra, 1997).

O balanço de calor em um sistema aquático representa, em síntese, a troca de calor com o ambiente circunvizinho (essencialmente a atmosfera). Devido à baixa condutividade térmica da água, a perda de radiação termal é predominantemente um fenômeno superficial, restrito aos primeiros centímetros da superfície do corpo d'água (Henderson-Sellers, 1986; Wetzel, 2001).

A estrutura termal resultante, a qual varia no tempo e no espaço em relação às condições externas são extremamente importantes para a troca de gases entre a superfície da água e a atmosfera (Ambrosetti et al., 2002); mudanças na estrutura térmica de sistemas aquáticos são dirigidas por interações complexas com a atmosfera (Robertson e Ragotzkie, 1990).

Modelos numéricos têm sido utilizados para integrar essas complexas interações permitindo a determinação de como mudanças específicas na atmosfera podem alterar a estrutura térmica de corpos d'água. Os modelos numéricos simulam os processos físicos que ocorrem no corpo d'água, sendo desenvolvidos principalmente para examinar mudanças que ocorrem sobre o curso de uma estação (Imberger, 1985) e interanuais (Beletsky e Schwab, 2001).

Outra ferramenta utilizada para estudar a distribuição da temperatura superficial da água no espaço e sua variabilidade no tempo é o sensoriamento remoto (Schott et al., 2001). Por oferecer uma visão sinótica da superfície da água e a possibilidade de estimar sua temperatura em períodos longos de tempo, alguns pesquisadores conduziram suas pesquisas utilizando imagens de satélite para documentar a temperatura superficial de sistemas aquáticos continentais (Schott et al., 2001; Li et al., 1999; Oesch et al., 2005).

Avanços na área de sensoriamento remoto permitem um monitoramento mais acurado dos sistemas aquáticos em geral (Alsdorf e Lettenmaier, 2003) e sua qualidade em particular (Vos et al., 2003). O uso de sensoriamento remoto no estudo do ciclo da temperatura em sistemas aquáticos de água doce tem crescido nos últimos anos (Bussières et al., 2002). A estimativa da temperatura da superfície da água tem sido realizada utilizando o sensor AVHRR (Advanced Very High Resolution Radiometer) a bordo dos satélites da série NOAA desde 1979 e do sensor ATSR (Along Track Scanning Radiometer) lançado em 1991. O sensor MODIS (Moderate Resolution Imaging Spectroradiometer) a bordo dos satélites Terra e Aqua (lançados em 1999 e 2002, respectivamente) devido a sua resolução temporal, tem demonstrado grandes possibilidades no estudo do ciclo térmico de sistemas aquáticos.

Apesar dos avanços na área de sensoriamento remoto orbital, esse método ainda está limitado à camada milimétrica da superfície da água. Além disso, a resolução temporal dos satélites atuais ainda não permitem observar variações de curto termo. Baseado nisso, alguns autores (Stech et al., 2006; Alcântara et al., 2010a) têm trabalhado com dados em alta frequência temporal, obtidos por meio de boias de monitoramento automático.

O objetivo deste trabalho é desenvolver um modelo conceitual termodinâmico para o reservatório hidrelétrico de Itumbiara.

\section{1. Área de estudo}

O Reservatório Hidrelétrico de Itumbiara $\left(18^{\circ} 25^{\prime} \mathrm{S}, 4^{\circ} 06^{\prime} \mathrm{W}\right)$ está localizado no bioma cerrado, na divisa dos estados de Minas Gerais, no Triângulo Mineiro, e Goiás e é formado, principalmente, pelo represamento dos rios Paranaíba, Araguari e Corumbá. Possui forma 
ALCÂNTARA, E. H. de; STECH, J. L. Desenvolvimento de modelo conceitual termodinâmico para o reservatório hidrelétrico de Itumbiara baseado em dados de satélite e telemétricos. Ambi-Agua, Taubaté, v. 6, n. 2, p. 157-179, 2011. (doi:10.4136/ambi-agua.192)

dendrítica, com $740 \mathrm{Km} 2$ de área inundada, 17,03 bilhões de m3 de volume de água, e, aproximadamente, $80 \mathrm{~m}$ de profundidade máxima durante a cheia, e $70 \mathrm{~m}$ durante a seca (Figura 1).

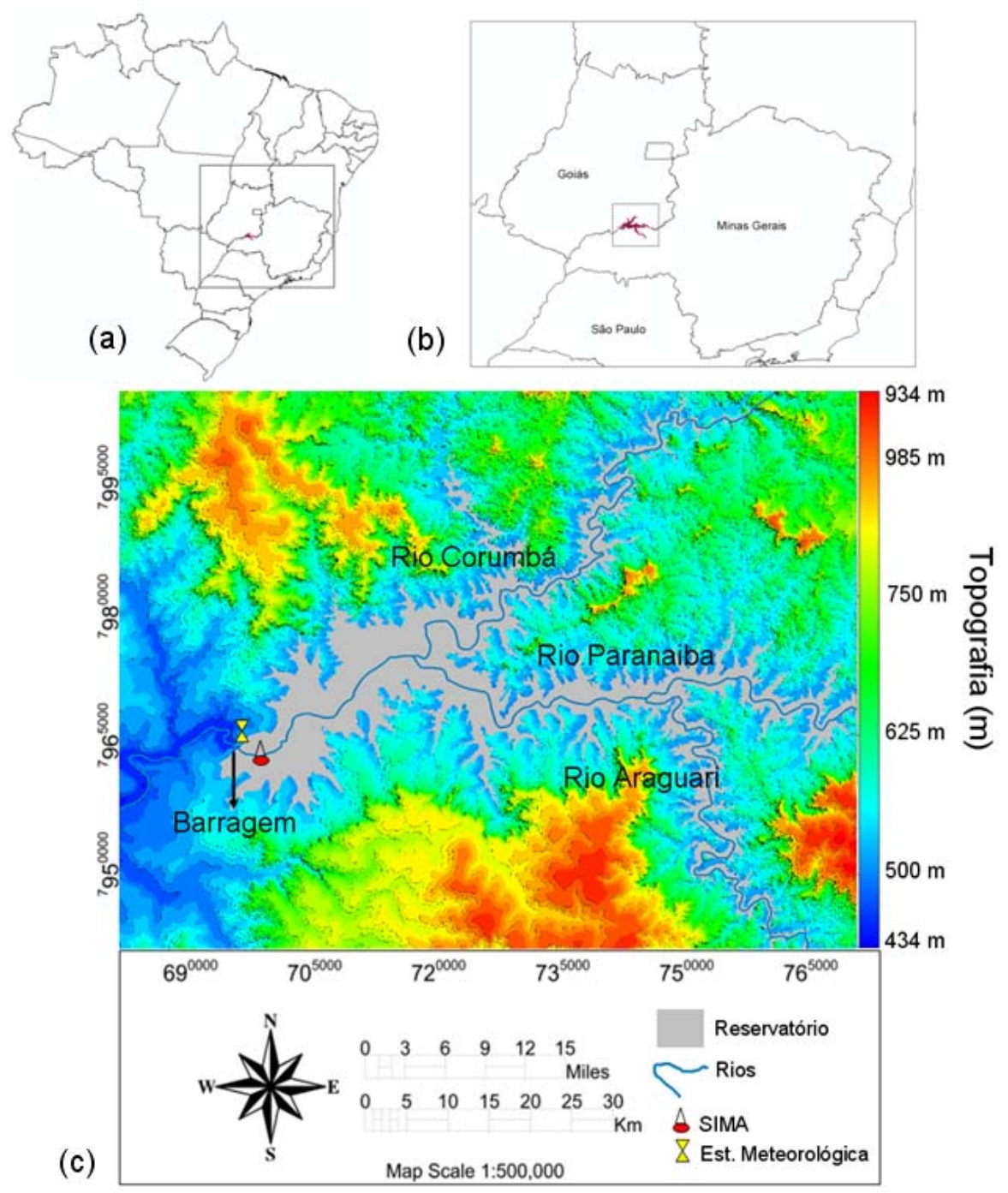

Figura 1. Localização do reservatório de Itumbiara na região central do Brasil (a), no contexto do estado do Goiás (b) a extensão da área inundada pelo reservatório, topografia e a localização da estação meteorológica e da boia de monitoramento automático SIMA (c).

O clima na região do reservatório é caracterizado por uma precipitação que varia de 2 mm durante a estação seca (maio - setembro) a $315 \mathrm{~mm}$ na estação chuvosa (outubro - abril). Durante a estação chuvosa, a intensidade dos ventos varia de 1,6 a 2,0 $\mathrm{ms}^{-1}$, podendo alcançar $3,0 \mathrm{~ms}^{-1}$ durante a estação seca (Figura 2-a). A temperatura do ar durante a estação chuvosa pode variar de 25 a $26,5^{\circ} \mathrm{C}$ e atingir o mínimo em junho $\left(21^{\circ} \mathrm{C}\right)$ na estação seca. A umidade relativa do ar possui uma variação cujo padrão é simular à temperatura do ar, com uma pequena variação no valor mínimo em setembro (47\%); durante a estação chuvosa a umidade pode atingir $80 \%$ (Figura 2-b).

Tomando como base a taxa de variação do nível da água no reservatório $\left(\frac{d C}{d t}\right)$, é possível classificar os estágios da água de acordo com o sugerido por Barbosa et al. (2006). O nível da água começa a subir em dezembro e se estende até maio (com taxa de variação média 
ALCÂNTARA, E. H. de; STECH, J. L. Desenvolvimento de modelo conceitual termodinâmico para o reservatório hidrelétrico de Itumbiara baseado em dados de satélite e telemétricos. Ambi-Agua, Taubaté, v. 6, n. 2, p. 157-179, 2011. (doi:10.4136/ambi-agua.192)

para o período de $\frac{d C}{d t}=0,031 \mathrm{~m} \mathrm{dia}^{-1}$ ); de maio a junho, o reservatório atinge o seu máximo de armazenamento de água (taxa de variação de, aproximadamente, 0,006 $\mathrm{m} \mathrm{dia}^{-1}$ ). Devido ao uso da água armazenada para geração de energia e abastecimento e às taxas de evaporação, o nível da água baixa até novembro (taxa de variação de aproximadamente $0,032 \mathrm{~m} \mathrm{dia}^{-1}$ ) e atinge seu menor nível de armazenamento em dezembro (taxa de variação de aproximadamente $0,023 \mathrm{~m} \mathrm{dia}^{-1}$ ). Esses dados foram úteis na seleção da melhor época para a amostragem de profundidades no reservatório.
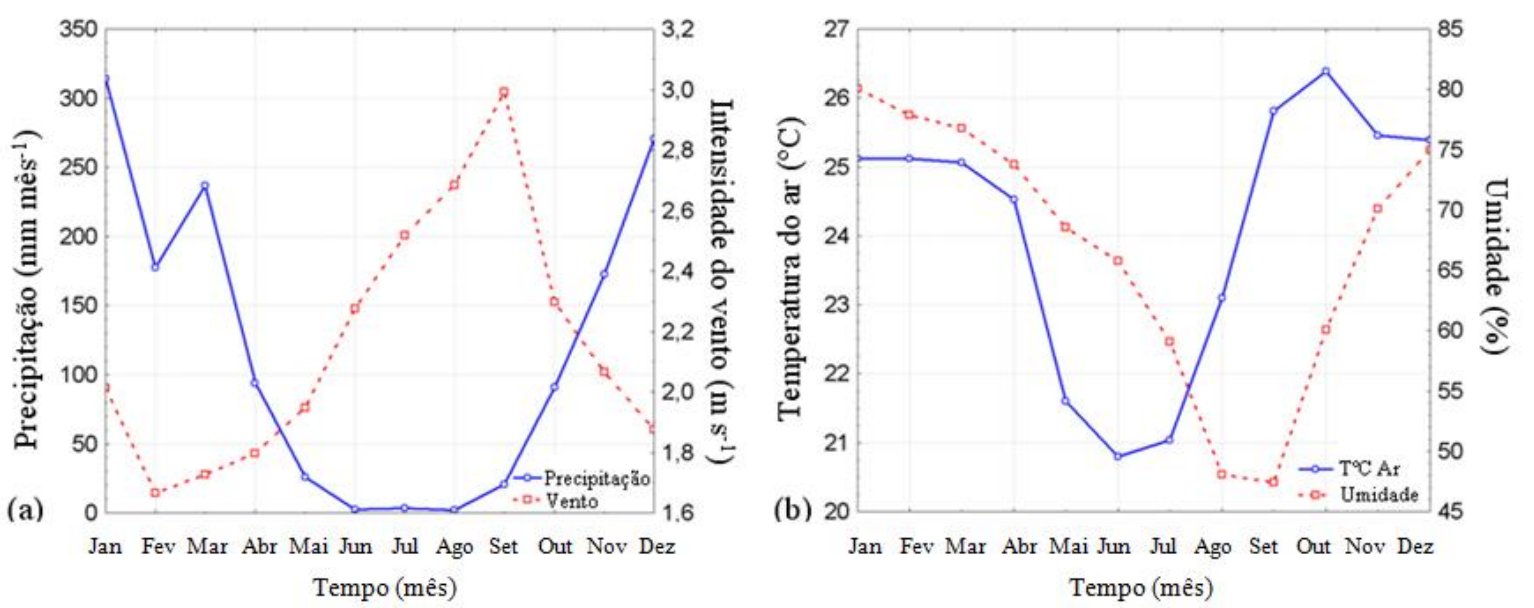

Figura 2. Caracterização climática da área do reservatório de Itumbiara por meio de uma média de 2003 a 2008.

Esse padrão hidroclimático e a rotina de operação do reservatório para geração de energia elétrica conduz à variação de nível da água no reservatório, e pode ser visualizado por meio da Figura 3.

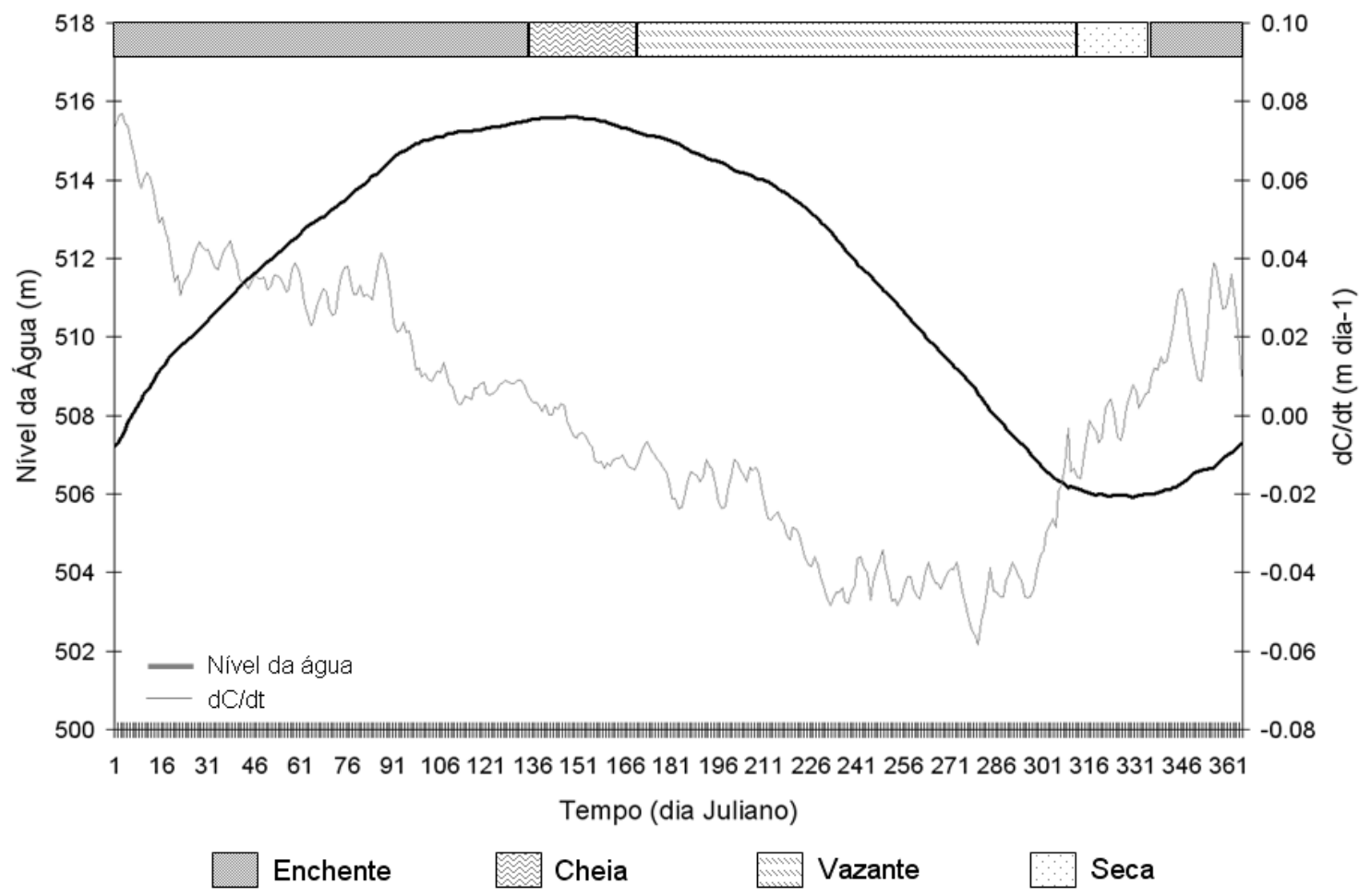

Figura 3. Variação média diária (2003-2008) do nível da água $(C)$ no reservatório e sua variação no tempo $(t)$. 
ALCÂNTARA, E. H. de; STECH, J. L. Desenvolvimento de modelo conceitual termodinâmico para o reservatório hidrelétrico de Itumbiara baseado em dados de satélite e telemétricos. Ambi-Agua, Taubaté, v. 6, n. 2, p. 157-179, 2011. (doi:10.4136/ambi-agua.192)

\section{MATERIAIS E MÉTODOS}

\subsection{Levantamento batimétrico}

A primeira campanha de campo para amostragem das profundidades no reservatório foi realizada entre 11-15 de maio de 2009, quando o nível da água pode ser considerado máximo (Figura 3). Como não foi possível cobrir toda a área do corpo principal do reservatório com apenas uma campanha de campo, uma segunda campanha foi realizada entre 11-16 de agosto de 2009.

O meio convencional de medir a profundidade de corpos d'água é por meio de transectos, utilizando-se cordas graduadas com um peso na ponta, a qual é baixada até o fundo do corpo d'água e sua posição (latitude/longitude) é anotada em conjunto com a profundidade do ponto. Um recente desenvolvimento tecnológico nos levantamentos batimétricos é o uso de um Sonar (Sound Navigation and Ranging) montado em uma embarcação, comumente chamado de ecobatímetro; este é acoplado a um GPS (Sistema de Posicionamento Global) podendo operar em duas frequências 50 e $200 \mathrm{KHZ}$. Esses sistemas têm a opção de gravar automaticamente uma série de dados $(\mathrm{x}, \mathrm{y}, \mathrm{z})$ em um cartão de memória o qual pode ser facilmente acessado via software proprietário (Merwade, 2009). A amostragem de profundidade no corpo principal do reservatório foi realizada utilizando-se um ecobatímetro LMS-525 da marca Lowrance.

Para delimitação do limite entre terra firme e área inundada no reservatório, uma cena do sensor TM a bordo do Landsat-5 de 26 de maio de 2007 (período de máximo nível de água no reservatório) foi adquirida. Depois de identificada a época do ano em que o máximo nível de água ocorre, a cena do sensor TM/Landsat-5 da área de estudo foi georreferenciada. Nessa cena foi aplicado o índice NDWI (Normalized Difference Water Index), (Mcfeeters, 1996) o qual tem como objetivo delimitar o que é água e o que não é; gerando uma máscara de terra. Essa cena TM foi utilizada para a construção das rotas ou malhas de amostragem de profundidades (Figura 4).

As rotas apresentadas na Figura 4 foram exportadas para o GPS por meio do software GPS TrackMaker. Em campo, de posse do GPS com as rotas e o ecobatímetro montado no barco, foi necessário apenas seguir as rotas e fazer a aquisição das profundidades que eram gravadas automaticamente pelo próprio equipamento por meio de um cartão de memória MMC. Estando esses dados em um formato adequado, o próximo passo foi a interpolação.

\subsubsection{Interpolação dos dados de profundidade medidos com ecobatímetro}

A interpolação dos dados de profundidade foi realizada utilizando-se o algoritmo de Krigeagem Ordinária (Isaaks e Srivastava, 1989), seguindo a metodologia descrita em Merwade (2009).

\subsection{Cálculo da área e volume do reservatório no tempo}

Utilizando-se a grade de profundidades obtida por meio da sondagem com ecobatímetro e com a cota média (1993-2003) mensal da água do reservatório (Figura 3), a área foi calculada por meio de rotinas do ArcGIS (ESRI, 2004) e o volume como sugerido por Chapra (1997), como segue:

$$
V=\int_{z_{0}}^{z_{m}} A(z) d z
$$

em que $A$ é a área $\left(\mathrm{m}^{2}\right)$ em uma dada profundidade $z(\mathrm{~m})$. 


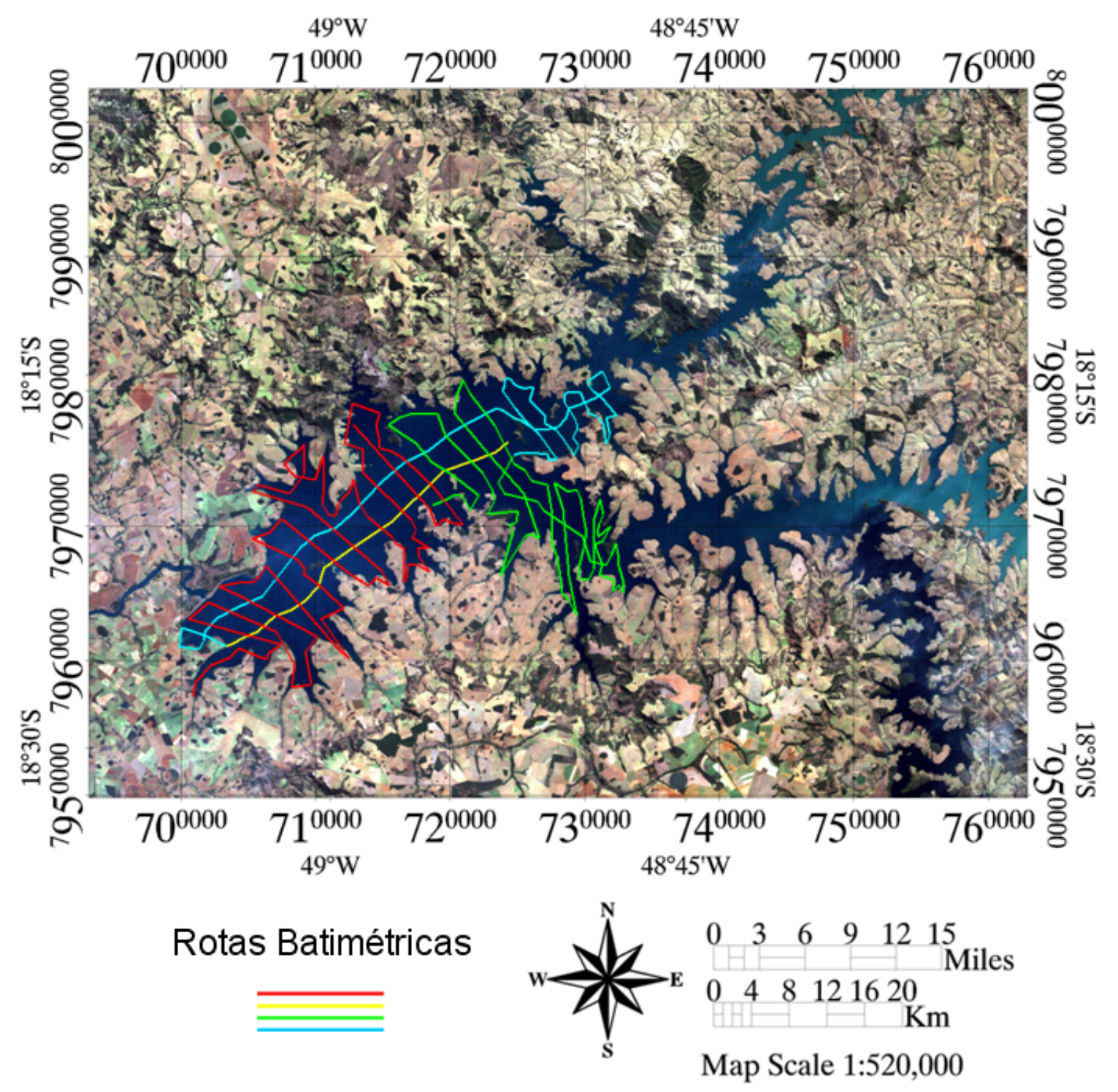

Figura 4. Rotas planejadas para medidas de profundidade utilizando-se o ecobatímetro.

\subsection{Dados medidos in-situ}

\subsubsection{Dados de temperatura da água, intensidade e direção do vento e evaporação}

Dados de temperatura da água em quatro níveis 5, 12, 20 e 40 metros e dados de vento (intensidade e direção) de 28 de março de 2009 a 17 de fevereiro de 2010 foram coletados (a cada 1 hora) por meio de um sistema automático de coleta de dados, denominado SIMA (Sistema Integrado de Monitoramento Ambiental, Figura 1-c). Esse sistema compõe-se de uma boia toroidal ancorada, instrumentada com sensores meteorológicos, de qualidade da água e uma cadeia de termistores. Os dados são coletados automaticamente e transmitidos via enlace dos satélites brasileiros (SCD-2, CBERS-1 ou CBERS-2, brasileiros, ou da série NOAA, americanos) e de um sistema de recepção dos sinais dos satélites (Stech et al., 2006).

Com o cálculo da área e volume variando ao longo do tempo e os dados de temperatura da água em quatro níveis obtidos pelo SIMA, foi possível estimar o conteúdo médio de calor armazenado por mês no reservatório. 
ALCÂNTARA, E. H. de; STECH, J. L. Desenvolvimento de modelo conceitual termodinâmico para o reservatório hidrelétrico de Itumbiara baseado em dados de satélite e telemétricos. Ambi-Agua, Taubaté, v. 6, n. 2, p. 157-179, 2011. (doi:10.4136/ambi-agua.192)

\subsubsection{Calor médio armazenado por mês}

O conteúdo de calor ( $\varsigma$, cal) para um dado volume de água armazenado no reservatório pode ser calculado utilizando-se a formulação dada por Chapra e Reckhow (1983):

$\varsigma=t \rho C V$

em que $t$ é a temperatura da água $\left({ }^{\circ} \mathrm{C}\right), \rho$ é a densidade da água $\left(\mathrm{gcm}^{-3}\right), C$ é o calor específico da água $\left(\mathrm{calg}^{-1_{0}} \mathrm{C}^{-1}\right)$, e $V$ é o volume de água $\left(\mathrm{cm}^{3}\right)$.

Para transformar a temperatura da água em calor $\left(\varsigma_{H}\right.$, cal $\left.\mathrm{cm}^{-2}\right)$, é assumido que o volume de um grama de água é $1 \mathrm{ml}$, e que o calor específico da água é $1 \mathrm{cal} \mathrm{g}^{-1}{ }^{\mathrm{o}} \mathrm{C}^{-1}$ (Wetzel e Likens, 2000):

$$
\varsigma_{H}=\sum_{Z_{0}}^{Z_{\text {MAX }}} t_{z} A_{z} h_{z}
$$

em que $z_{0}$ é a superfície do reservatório, $z_{m}$ é a profundidade máxima $(\mathrm{m}), t_{z}$ é a temperatura $\left({ }^{\circ} \mathrm{C}\right)$ média em cada camada de espessura $h_{z}(\mathrm{~cm})$, com ponto central na profundidade $(\mathrm{z})$ e $A_{z}$ é a área à profundidade $z\left(\mathrm{~cm}^{2}\right)$. A obtenção de $\varsigma_{H}$ é realizada por meio da multiplicação do volume $\left(\mathrm{cm}^{3}\right)$ pela temperatura média $\left({ }^{\circ} \mathrm{C}\right)$ em cada camada $\left({ }^{\circ} \mathrm{C} \mathrm{cm}^{3}\right)$ dividida pela área superficial do reservatório $\left(\mathrm{cm}^{2}\right)$, do qual se obtém o conteúdo calórico em cal $\left./ \mathrm{cm}^{2}\right)$. Os dados de temperatura in-situ por profundidade serão obtidos por meio de um sistema automático de coleta de dados limnológicos (SIMA, Figura 1-c).

\subsection{Dados de sensoriamento remoto termal}

O sensoriamento remoto orbital por meio de sistemas ópticos, ou seja, que operam na faixa do visível e infravermelho do espectro eletromagnético representa atualmente uma ferramenta importante para estudos em sistemas aquáticos. Existem várias plataformas em operação, oferecendo diferentes opções de resolução espacial, temporal, espectral e radiométrica, de acordo com as necessidades de cada aplicação. Em especial, pode-se destacar o sensor EOS-MODIS.

O sensor MODIS (Moderate Resolution Imaging Spectroradiometer), a bordo dos satélites EOS-TERRA e EOS-AQUA do programa Earth Observing System (EOS) da Agência Espacial Americana (National Aeronautics and Space Administration - NASA), reúne um conjunto de características inéditas, que o capacitam para a realização de estudos em diversas áreas do conhecimento.

O produto MOD11A1 utilizado neste trabalho foi a versão 5 com processamento L $3^{1}$. A versão V5 foi selecionada por apresentar refinamentos em relação aos seus antecessores, tais como considerar a elevação da área imageada, utilizar máscara de nuvens, remoção de pixels contaminados por nuvens e correção atmosférica (Wan, 2008). Além disso, em um estudo conduzido por Oesch et al. (2005) em três lagos da Europa, o produto de temperatura de superfície do MODIS/Terra apresentou menor erro do que o do MODIS/Aqua.

De acordo com Wan et al. (2004), o produto MOD11A1 possui uma acurácia de aproximadamente $1^{\circ} \mathrm{C}$ no limite de variação de -10 a $50^{\circ} \mathrm{C}$. s dados de temperatura são tomados durante o dia $(\sim 10 \mathrm{~h} 30 \mathrm{~min})$ e noite $(\sim 23 \mathrm{~h} 30 \mathrm{~min})$. O algoritmo utilizado para a estimativa da temperatura de superfície é:

\footnotetext{
${ }^{1} \mathrm{O}$ nível de processamento L3 é um produto geofísico que foi temporal ou espacialmente manipulado (Wan, 2008).
} 
ALCÂNTARA, E. H. de; STECH, J. L. Desenvolvimento de modelo conceitual termodinâmico para o reservatório hidrelétrico de Itumbiara baseado em dados de satélite e telemétricos. Ambi-Agua, Taubaté, v. 6, n. 2, p. 157-179, 2011. (doi:10.4136/ambi-agua.192)

$$
\begin{aligned}
& M_{O D I S_{S S T}}=C 1+C 2(T 31)+C 3(T 32-T 31)\left(S S T_{\text {guess }}\right) \\
& +C 4(\text { Secq }-1)(T 32-T 31)
\end{aligned}
$$

em que T31 e T32 são a temperatura de brilho dos canais 31 e 32 do sensor MODIS, respectivamente; $S S T_{\text {guess }}$ é um primeiro palpite para a temperatura da superfície e sec é o secante do ângulo zenital do satélite $(q)$. Esse algoritmo distingue o conteúdo de vapor de água entre a baixa e alta atmosfera por meio do uso de dois pares de coeficientes, $C 1-C 4$, dependendo da diferença de temperatura de brilho entre os canais 31 e 32 do MODIS.

Para o produto de temperatura diurno, a interpolação ótima (IO) de Reynolds (Reynolds e Smith, 1994) foi utilizada como um primeiro palpite $\left(S S T_{\text {guess }}\right)$ e o produto de temperatura do infravermelho médio foi utilizado para o produto de temperatura de superfície noturno (Oesch et al., 2005).

Somente as cenas $100 \%$ livres de nuvens e ao nadir foram utilizadas; por isso, para o produto dia foram descartadas 1404 cenas e para o produto noite foram descartadas 1717, de um total de 4380 imagens disponíveis durante o dia e noite. A Figura 5 mostra o horário de passagem do satélite Terra na aquisição dos dados de temperatura dia e noite.
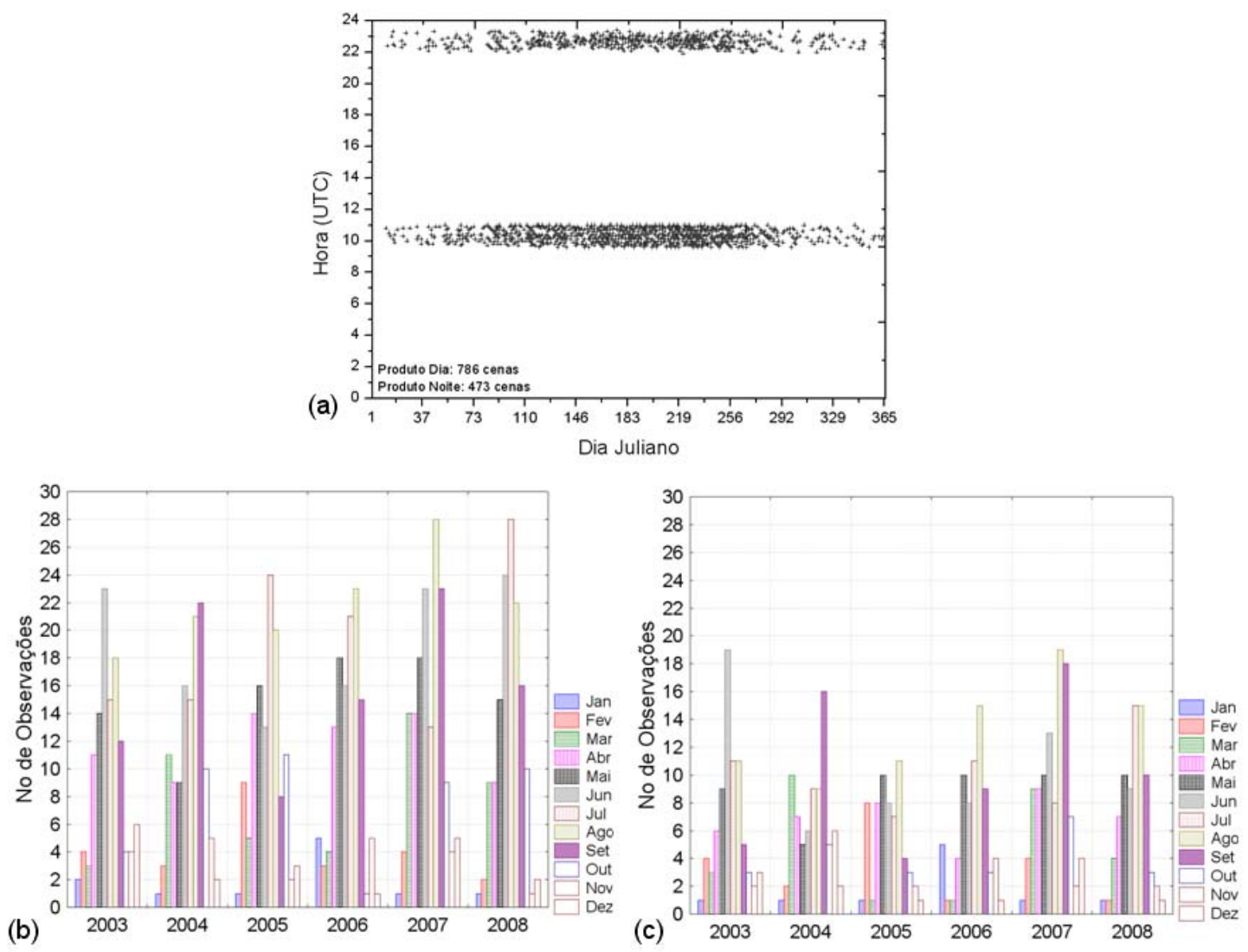

Figura 5. Informações sobre o dia Juliano e horário de aquisição das cenas (a) e o número de observações das cenas tomadas durante o dia (b) e noite (c) de 2003 a 2008.

Da Figura 5, pode-se observar que, das 786 cenas (produto dia) e 473 cenas (produto noite) adequadas à análise da temperatura da superfície da água, a maioria está concentrada nos meses de junho, julho e agosto (período de estiagem) e os meses de janeiro, fevereiro, novembro e dezembro (período de chuva), os meses com menor concentração de cenas. 
ALCÂNTARA, E. H. de; STECH, J. L. Desenvolvimento de modelo conceitual termodinâmico para o reservatório hidrelétrico de Itumbiara baseado em dados de satélite e telemétricos. Ambi-Agua, Taubaté, v. 6, n. 2, p. 157-179, 2011. (doi:10.4136/ambi-agua.192)

Essas cenas foram utilizadas para a análise de padrões na temperatura da superfície da água medida durante o dia e a noite e para o balanço de calor na superfície da água do reservatório.

\subsection{Estimativa dos fluxos de calor na superfície da água}

A estimativa do balanço de calor entre a superfície da água e a atmosfera foi realizada seguindo a metodologia descrita em Lofgren e Zhu (2000) e Zapadka et al. (2008). Para tanto, dados meteorológicos foram utilizados para realizar essa tarefa. Os dados diários de temperatura do $\operatorname{ar}\left({ }^{\circ} \mathrm{C}\right)$ e intensidade do vento $\left(\mathrm{ms}^{-1}\right)$ dos anos de 2003 a 2008 foram obtidos por meio da estação meteorológica de Furnas Centrais Elétricas S.A. instalada no reservatório de Itumbiara. Dados de temperatura da água $\left({ }^{\circ} \mathrm{C}\right)$ foram obtidos por meio das imagens MODIS para a mesma janela de tempo. Todas as análises realizadas para os dados de temperatura da superfície da água também foram realizadas nos dados de fluxos de calor.

$\mathrm{O}$ saldo de energia $\left(\phi_{N}, \mathrm{Wm}^{-2}\right)$ na superfície de lagos e reservatórios incluem radiação solar, radiação que retorna da superfície da água, radiação atmosférica, perda de calor por evaporação e condução. Este saldo pode ser calculado como segue (Henderson-Sellers, 1986; Martin e Mccutcheon, 1999; Alcântara et al. 2010b):

$$
\phi_{N}=\phi_{s}(1-A)-\left(\phi_{r i}+\phi_{s f}+\phi_{l f}\right)
$$

em que $\phi_{N}$ é o saldo de energia disponível, $\phi_{s}$ é a radiação de onda curta incidente, $A$ é o albedo da água $(=0,07), \phi_{r i}$ é o fluxo de onda longa, $\phi_{s f}$ é o fluxo de calor sensível e $\phi_{l f}$ é o fluxo de calor latente.

\subsection{Modelo conceitual térmico da água do reservatório}

Tomando como base os resultados obtidos com os mapas de temperatura da superfície da água do reservatório, o balanço de calor e os dados limnológicos e meteorológicos in situ foi possível idealizar modelos conceituais para a termodinâmica do reservatório. Os modelos foram divididos em três condições térmicas: (1) início da estratificação, (2) mistura da coluna d'água e (3) volta da estratificação da água no reservatório.

\section{RESULTADOS}

\subsection{Batimetria e dinâmica de área e volume no reservatório}

Os dados de profundidades obtidos por meio da sondagem com ecobatímetro e posteriormente interpolados mostram que próximo da barragem e onde escoava o rio antes da inundação, são os locais mais profundos do reservatório (Figura 6).

Próximo à barragem foi realizado um processo de dragagem com o objetivo de deixar o local mais profundo para que fosse possível colocar a tomada d'água em uma profundidade desejada (aproximadamente 80 metros segundo informações de FURNAS Centrais Elétricas). Como esperado as regiões mais profundas são àquelas onde os rios passavam antes da inundação, caracterizando a região como tendo o formado de vale. Esse formato de vale é um dos pré-requisitos para a instalação de uma hidrelétrica, pois permite um maior armazenamento de água. A carta batimétrica também mostra que o rio Paranaíba é mais profundo do que o rio Corumbá.

Na Figura 6, é possível observar que a amostragem não foi realizada em toda a extensão dos rios que foram barrados para a construção hidrelétrica. Isso ocorreu principalmente devido ao elevado custo desse tipo de amostragem. No entanto, o corpo principal do reservatório foi devidamente coberto, sendo a região mais importante em área e volume. 
ALCÂNTARA, E. H. de; STECH, J. L. Desenvolvimento de modelo conceitual termodinâmico para o reservatório hidrelétrico de Itumbiara baseado em dados de satélite e telemétricos. Ambi-Agua, Taubaté, v. 6, n. 2, p. 157-179, 2011. (doi:10.4136/ambi-agua.192)

Utilizando-se de rotinas computacionais foi possível realizar o cálculo da variação de área $\left(\mathrm{m}^{2}\right)$ e volume $\left(\mathrm{m}^{3}\right)$ ao longo de um ano (Figura 7). Nesse caso, notar que a variação de cota utilizada nesse cálculo foi a obtida por meio de uma média entre os anos de 1993 a 2008.

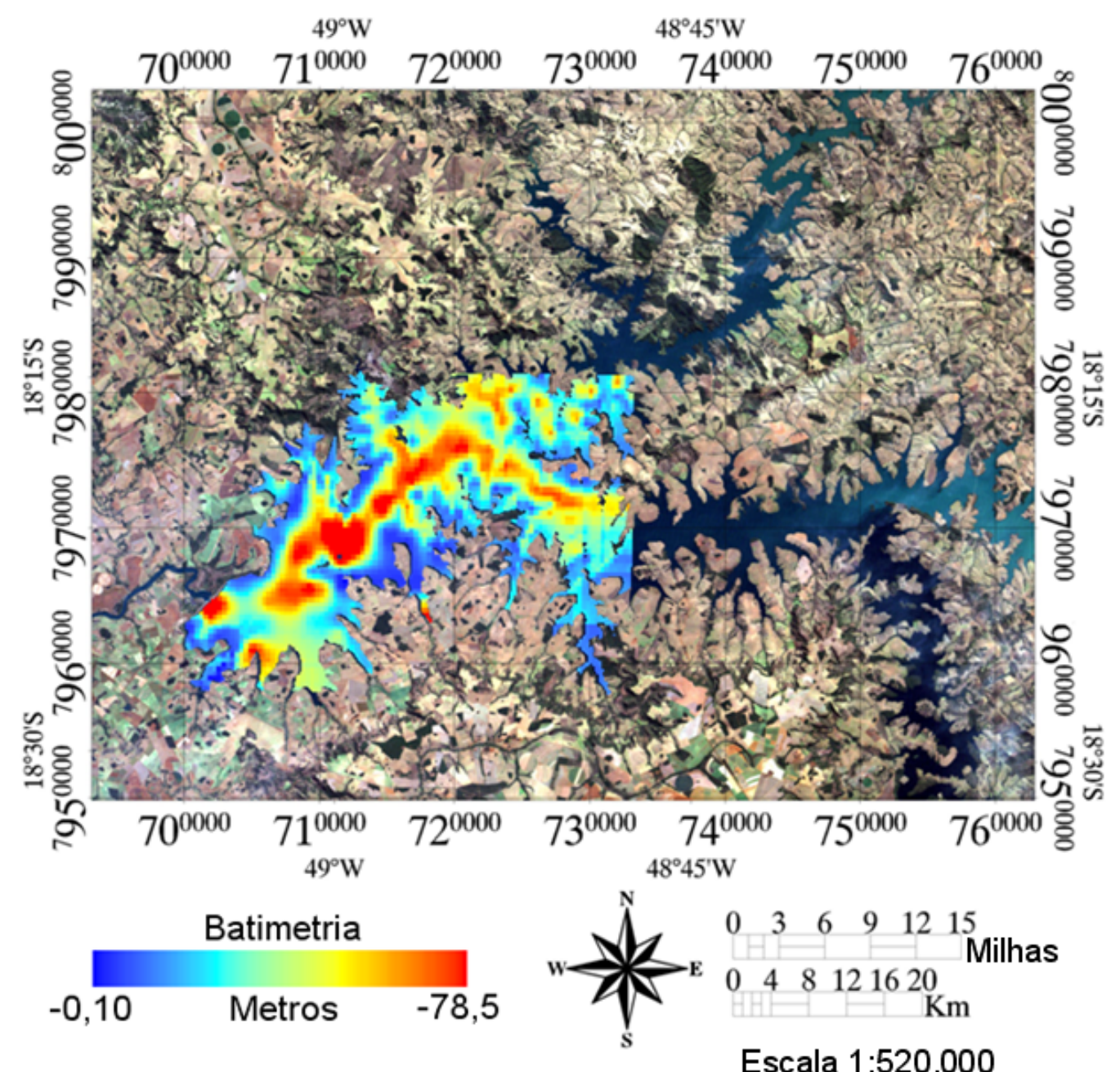

Figura 6. Batimetria do reservatório de Itumbiara.

A forma da curva da área e volume segue o mesmo padrão da variação da cota da água no reservatório (Figura 3); onde a maior área inundada e volume ocorrem em maio (351.292.000,00 $\mathrm{m}^{2}$ e 2.345.610.660,00 $\mathrm{m}^{3}$, respectivamente); e a menor em novembro $\left(309.020 .534 \mathrm{~m}^{2}\right.$ e $\left.2.063 .359 .995 \mathrm{~m}^{3}\right)$. Esse fato mostra que há uma diferença de área e volume entre os períodos de máximo e mínimo no reservatório de $40.345 .964,56 \mathrm{~m}^{2}$ e 269.393.907,50 $\mathrm{m}^{3}$, respectivamente, ou seja, cerca de $11,49 \%$.

Essas variações de área e volume são de extrema importância para os processos de estratificação e mistura em reservatórios e, consequentemente, na temperatura de superfície resultante (Rodríguez-Rodríguez et al., 2004). Além disso, essas variações auxiliam na estimativa do conteúdo de calor durante o período de um ano.

\subsubsection{Conteúdo médio de calor armazenado no reservatório}

Como mostra a Figura 8, o conteúdo de calor no reservatório se apresenta inversamente proporcional ao volume armazenado no reservatório (Figura 7). O resultado da estimativa do conteúdo de calor no tempo para o reservatório mostrou que o sistema começa a acumular calor de julho $\left(12453,35 \mathrm{cal} \mathrm{cm}^{-2}\right.$ mês $\left.^{-1}\right)$ a fevereiro $\left(19618,28 \mathrm{cal} \mathrm{cm}^{-2}\right.$ mês $\left.\mathrm{s}^{-1}\right)$ quando atinge o máximo armazenamento; a partir de março $\left(18561,43 \mathrm{cal} \mathrm{cm}^{-2} \mathrm{mês}^{-1}\right)$, o sistema começa a 
ALCÂNTARA, E. H. de; STECH, J. L. Desenvolvimento de modelo conceitual termodinâmico para o reservatório hidrelétrico de Itumbiara baseado em dados de satélite e telemétricos. Ambi-Agua, Taubaté, v. 6, n. 2, p. 157-179, 2011. (doi:10.4136/ambi-agua.192)

perder o calor armazenado atingindo o mínimo de calor no mês de junho $\left(11949,43 \mathrm{cal} \mathrm{cm}^{-2}\right.$ mês $\left.^{-1}\right)$. A diferença média entre o mês de maior armazenamento de calor e o menor é de aproximadamente $7668,84\left(\mathrm{cal} \mathrm{cm}^{-2}\right.$ mês $\left.^{-1}\right)$.

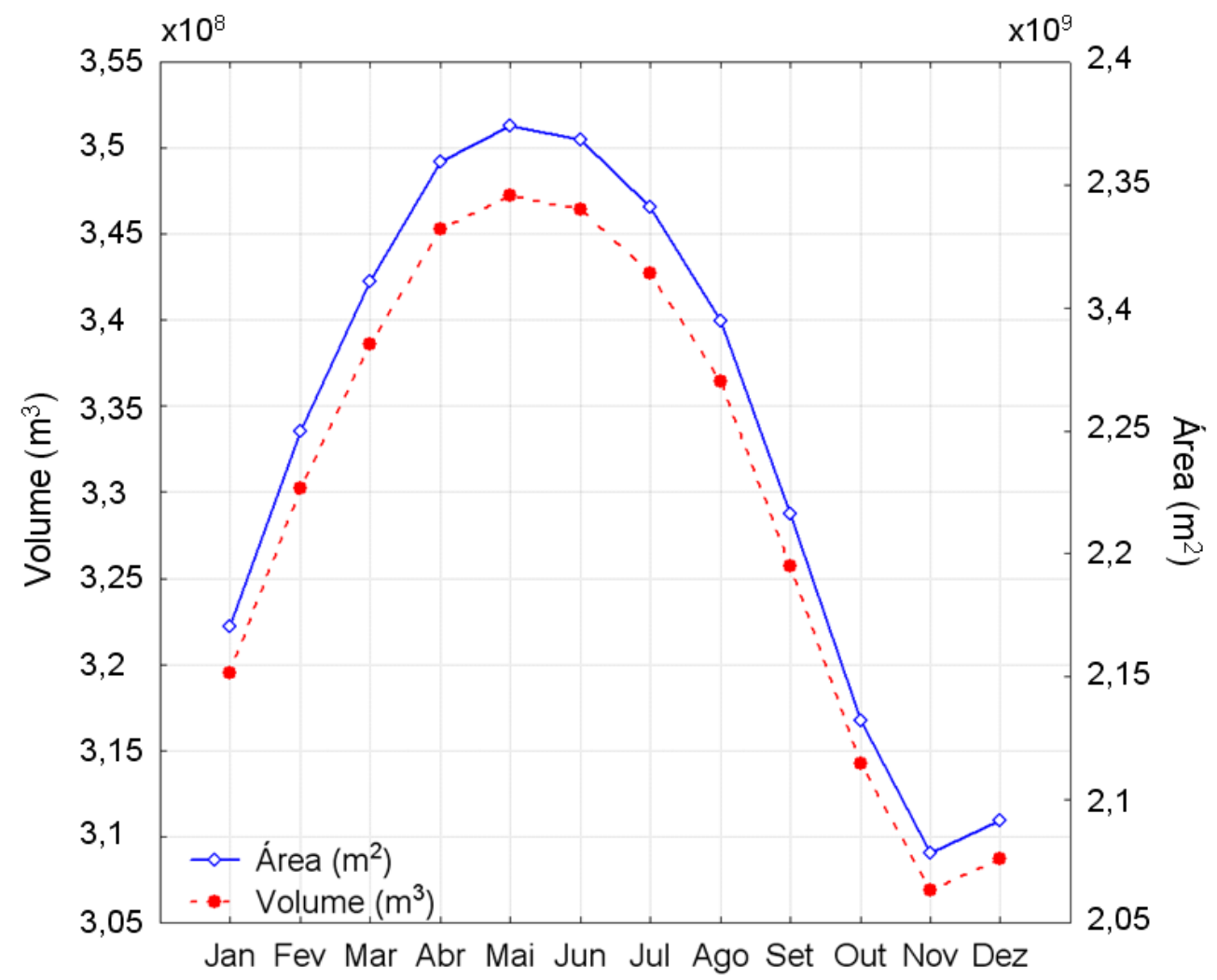

Figura 7. Variação mensal da área $\left(\mathrm{m}^{2}\right)$ e volume $\left(\mathrm{m}^{3}\right)$ no reservatório.

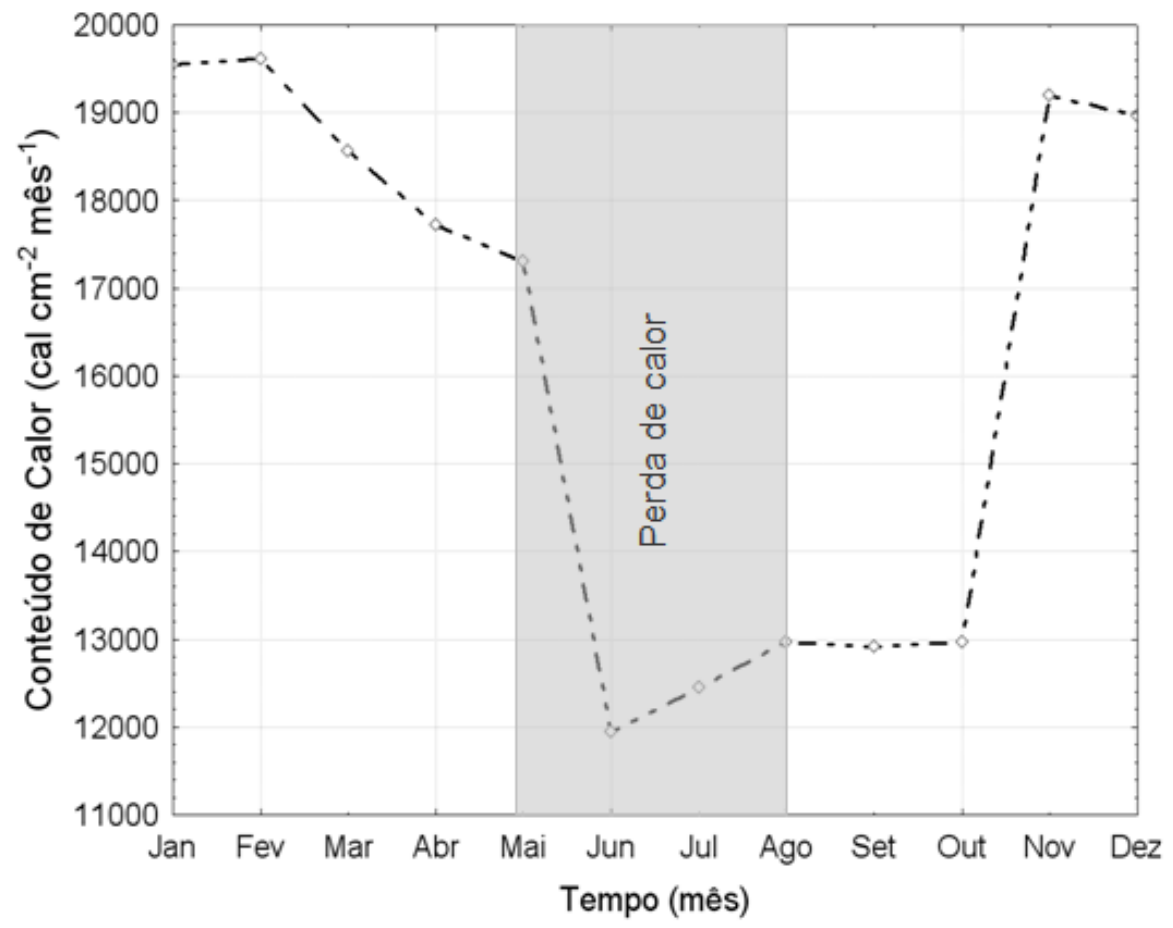

Figura 8. Mudança no conteúdo de calor $\left(\mathrm{cal} \mathrm{cm}^{-2}\right.$ mês $\left.{ }^{-1}\right)$ médio por mês no reservatório de Itumbiara. 
ALCÂNTARA, E. H. de; STECH, J. L. Desenvolvimento de modelo conceitual termodinâmico para o reservatório hidrelétrico de Itumbiara baseado em dados de satélite e telemétricos. Ambi-Agua, Taubaté, v. 6, n. 2, p. 157-179, 2011. (doi:10.4136/ambi-agua.192)

Esse padrão de armazenamento de calor na coluna d'água no reservatório poderá ser melhor verificado por meio do campo de temperatura na superfície da água. Nesse sentido, dados do campo de temperatura foram obtidos por meio das imagens MODIS/Terra.

\subsection{Sensoriamento remoto da temperatura da superfície da água}

A Figura 9 abaixo mostra a distribuição de temperatura média mensal obtida para o dia e a noite no reservatório de Itumbiara. De forma geral, as temperaturas para o dia apresentam um padrão em que a temperatura decresce da borda (limite água/terra) para o centro de massa do reservatório (região mais profunda); para a noite, o padrão é invertido.

$\mathrm{O}$ fato de a temperatura na borda do reservatório ser maior do que o centro durante o dia está relacionado à baixa profundidade e ao volume da borda. Essa região com baixo volume permite que a radiação de onda curta proveniente do Sol penetre até o fundo, fazendo com que toda a camada de água se aqueça. Ou seja, o calor é passado de uma camada a outra, de cima para baixo, tornando com o tempo a temperatura na borda homogênea. Como nesse caso a estratificação durante o dia é improvável não correm processos convectivos.

Já a região central do reservatório, onde a profundidade é maior e, consequentemente, maior volume, o aquecimento da água é mais lento uma vez que a massa d'água imediatamente inferior à superfície está mais fria, devido à condução de calor ou transferência de calor para camadas mais profundas. Isso permite a ocorrência da termoclina, ou gradiente de temperatura com a profundidade. Mas a maior diferença entre a região mais profunda e a borda do reservatório é a influência da terra na transferência de calor para as regiões mais rasas na interface terra/água.

Durante a noite, esse processo se inverte, pois a região mais rasa sob influência da temperatura em terra passa a perder calor mais rapidamente, também devido ao seu pequeno volume. Como a terra perde calor mais rapidamente do que a água (devido ao alto calor específico da água) a temperatura da terra será mais baixa do que da água, favorecendo ainda mais a perda de calor da interface terra/água.

No centro do reservatório, a influência da terra é mínima, exercendo maior influência os processos na interface água/atmosfera e dos processos físicos na coluna d'água. Esses processos físicos podem ser as ondas internas, causadas devido a processos convectivos, por exemplo. No entanto, esses processos convectivos são mais comuns quando a coluna d'água deixa de ser estratificada para se tornar misturada. Nesse caso alguns parâmetros são importantes na geração desses processos convectivos como a ação do vento agindo na superfície da água.

Os mapas do campo de temperatura dia dos meses de abril e maio mostram pequenas áreas na borda (caso do mês de abril) e no centro do reservatório (caso do mês de maio) com temperaturas menores do que as áreas circunvizinhas, mostrando a ocorrência da ressurgência de massas d'água mais frias oriundas de camadas mais profundas para a superfície. Esse tipo de processo em sistemas aquáticos é de suma importância, pois torna disponíveis nutrientes para a coluna d'água. Além disso, a ocorrência desse tipo de processo mostra que houve uma quebra da estabilidade da coluna d'água, o que também contribui para que as camadas mais profundas se tornem mais oxigenadas, com renovação de massas d'água.

\subsection{Saldo de radiação efetivo}

O saldo efetivo de radiação no contexto espacial pode ser visto na Figura 10. Para janeiro, fevereiro e abril a porção nordeste do reservatório ganha mais calor do que a sudeste. Isso é devido à direção preferencial do vento no reservatório ser de sudeste para nordeste, então o vento empurra a massa d'água aquecida para a região litorânea por meio da advecção; em março, a região sudeste aquece mais do que a nordeste. Em maio, uma grande área do 
reservatório perde calor, e somente uma pequena área no corpo principal ganha efetivamente calor. De junho a julho, a perda de calor domina o reservatório, as perdas na porção nordeste são menores do que as da porção sudeste. De agosto a dezembro, o reservatório aquece novamente da zona litorânea para o centro do reservatório; com a ressalva de que em outubro, existe um gradiente entre a zona litorânea e o centro do reservatório mais acentuado.

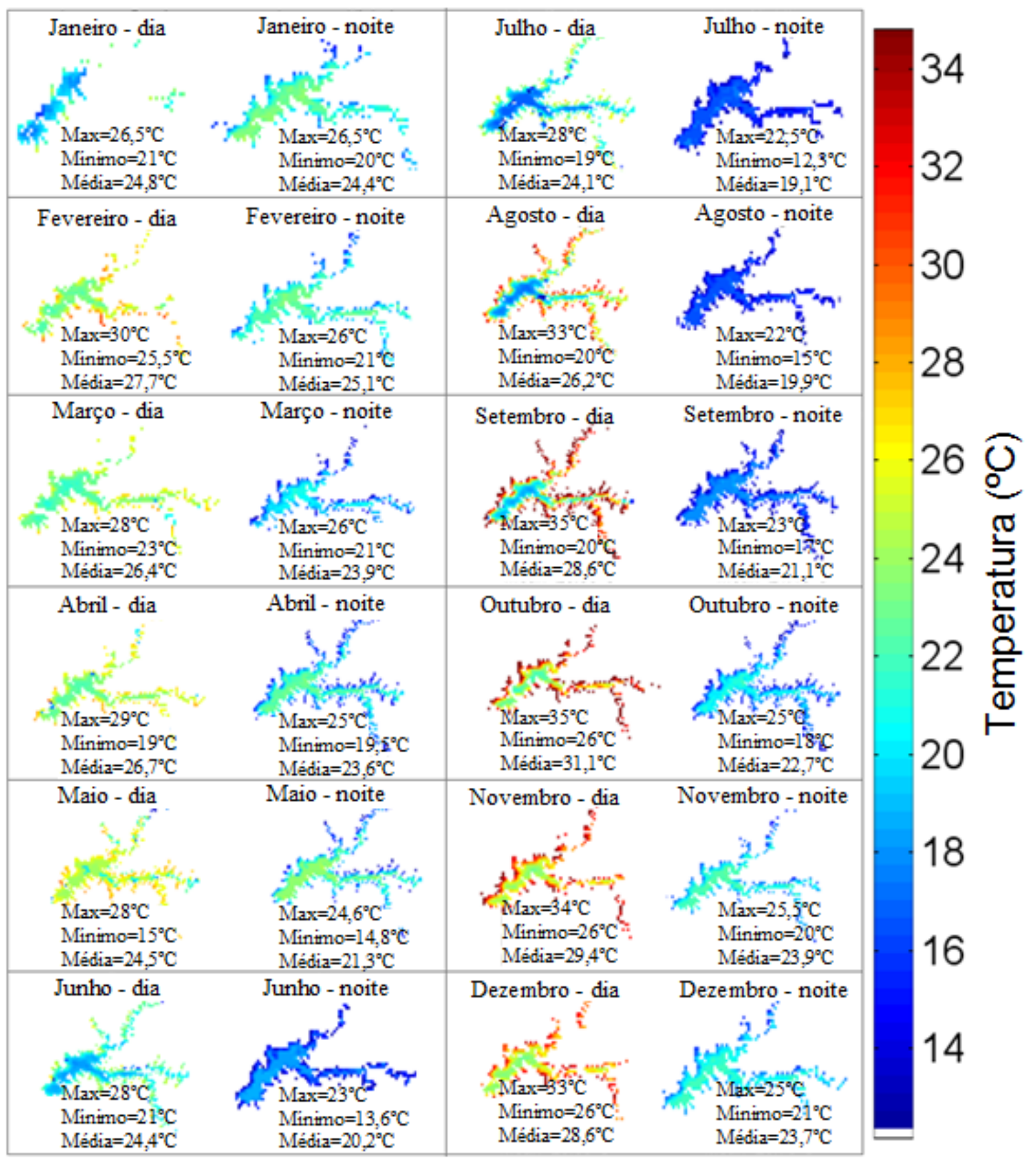

Figura 9. Mapas do campo de temperatura média mensal para o dia e a noite entre os anos de 2003 a 2008.

\subsection{Variação temporal da temperatura da coluna d'água}

Esse padrão também foi observado com os dados de temperatura coletados in situ pela boia SIMA (Figura 1, localização do SIMA no reservatório), de 28-mar-2009 a 12-fev-10 em quatro níveis 5, 12, 20 e 40 metros de profundidade (Figura 11). O que se observa nos dados 
in situ é que de junho a setembro a coluna d'água mistura e estratifica de outubro a maio. Isso permite classificar o reservatório de Itumbiara como monomítico, ou seja, apresenta um único período de mistura durante o ano. Durante o período de mistura, eventos de ressurgência (upwelling, Upw) e penetração de água mais densa (downwelling, Dwn) podem ocorrer devido à mistura convectiva (WÜEST e LORKE, 2003).

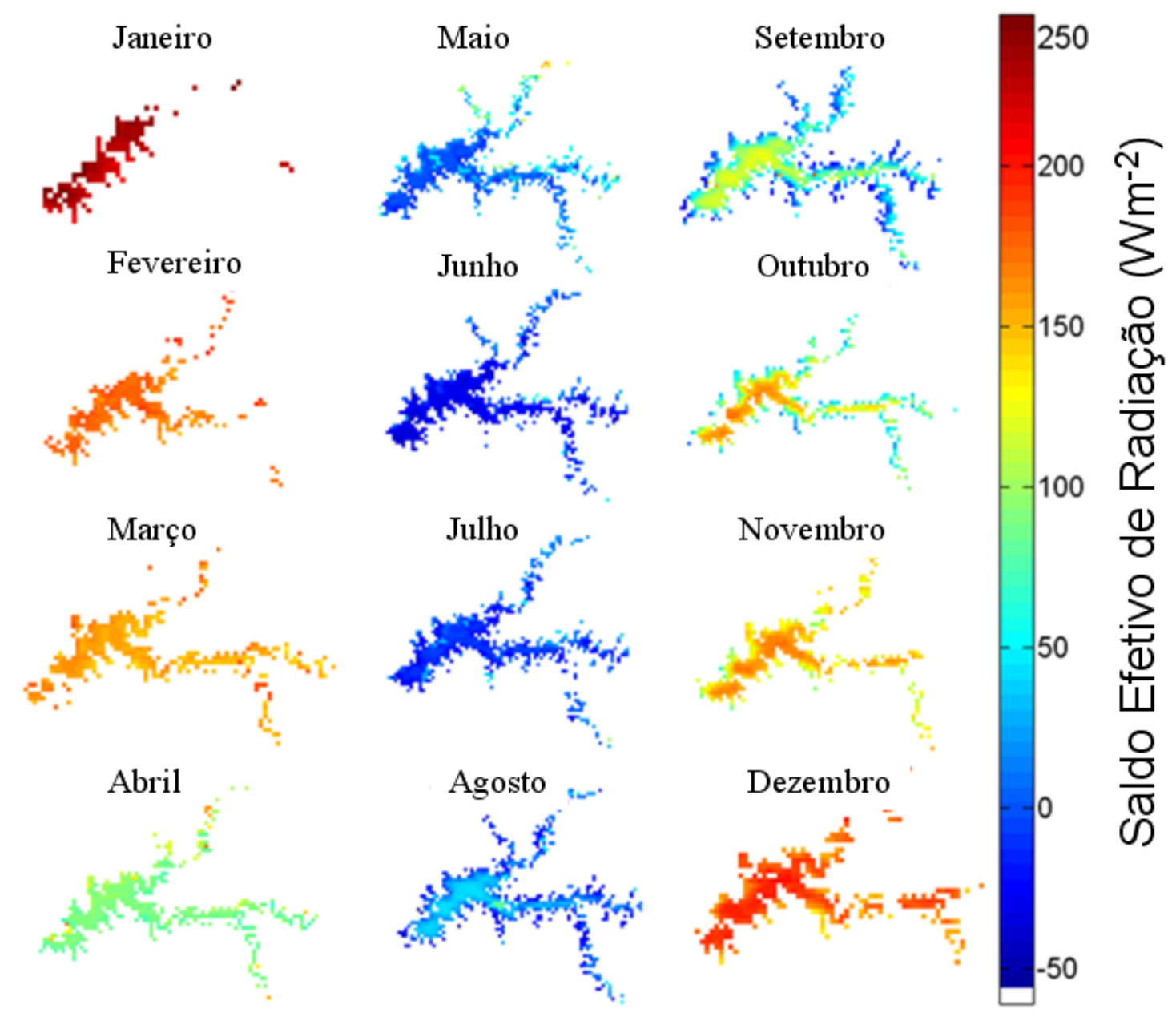

Figura 10. Variação espacial do saldo efetivo de radiação na superfície da água do reservatório.

\subsection{Modelo conceitual termodinâmico}

\subsubsection{De janeiro a maio: estratificação acentuada}

A Figura 12 mostra o modelo conceitual para a termodinâmica no reservatório de janeiro a maio. Nessa figura é possível visualizar os valores médios dos componentes do fluxo de calor para o período, e alguns processos internos. É um período chuvoso, com ventos de baixa intensidade, com direção preferencial de leste, mas com o vento atuando em todas as direções com menor intensidade; temperatura do ar alta (evaporação média de $131 \mathrm{~mm} \mathrm{mês}{ }^{-1}$ ), mas que decresce de janeiro a maio, assim como a umidade do ar.

Durante o dia, a radiação incidente atua fortemente na superfície da água, e nos dias em que não chove, essa radiação termal é transmitida para as camadas mais profundas $(\delta)$, e, nos dias nublados, a radiação de onda longa é a maior fonte de radiação para a superfície do 
ALCÂNTARA, E. H. de; STECH, J. L. Desenvolvimento de modelo conceitual termodinâmico para o reservatório hidrelétrico de Itumbiara baseado em dados de satélite e telemétricos. Ambi-Agua, Taubaté, v. 6, n. 2, p. 157-179, 2011. (doi:10.4136/ambi-agua.192)

reservatório. Geralmente a região rasa aquece mais rapidamente do que a região central do reservatório onde a profundidade é maior.

Nos meses de abril e maio podem ocorrer eventos de ressurgência parcial e total devido à desestabilização da coluna d'água; esses eventos podem ocorrer em locais isolados do reservatório.

Durante a noite predomina a perda de calor para atmosfera, mas no verão a temperatura da água durante a noite pode ser mais alta $\left(\right.$ até $6^{\circ} \mathrm{C}$ ) do que a temperatura da água durante o dia.

As regiões rasas do reservatório perdem calor mais rapidamente devido a seu pequeno volume e à influência da brisa de lago. Essa água mais fria e densa escoa como corrente de densidade profunda em sentido às regiões mais profundas, devido ao perfil batimétrico do reservatório; essa corrente pode acontecer também via superfície, quando a temperatura da água adjacente é mais fria. Quando a temperatura da corrente de densidade de superfície diminui ou encontra uma temperatura maior, essa água pode 'mergulhar', gerando um gradiente horizontal

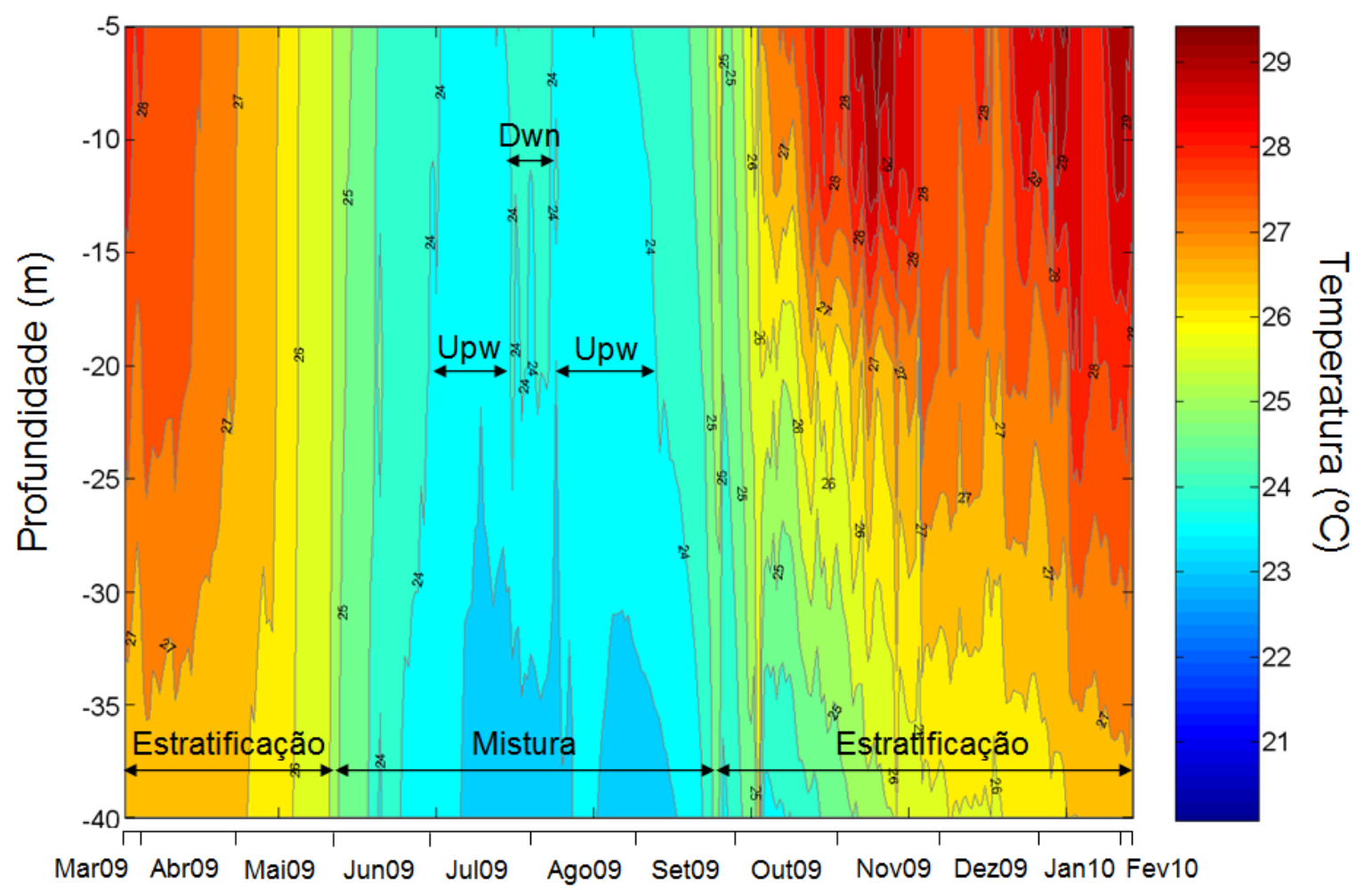

Figura 11. Variação temporal da temperatura da coluna d'água no reservatório de Itumbiara. Em que Upw $=$ ressurgência e Dwn $=$ entranhamento.

\subsubsection{De junho a setembro: mistura da coluna d'água}

A Figura 13 mostra o modelo conceitual para a termodinâmica no reservatório de junho a setembro, período em que o reservatório sai de um estado estratificado para um estado misturado.

Durante o dia, as regiões mais rasas tendem a aquecer durante os meses de setembro e outubro e nos meses de junho e julho existe um resfriamento no centro do reservatório mais acentuado. Devido ao aquecimento nas regiões rasas, por advecção esta é transportada no mesmo sentido da direção do vento: no final da atuação do vento pode ocorrer o afundamento de uma massa d'água mais quente, e na região onde o vento se iniciou pode ocorrer uma 
ressurgência de uma massa d'água mais fria; esse processo pode gerar uma condição de convecção turbulenta.

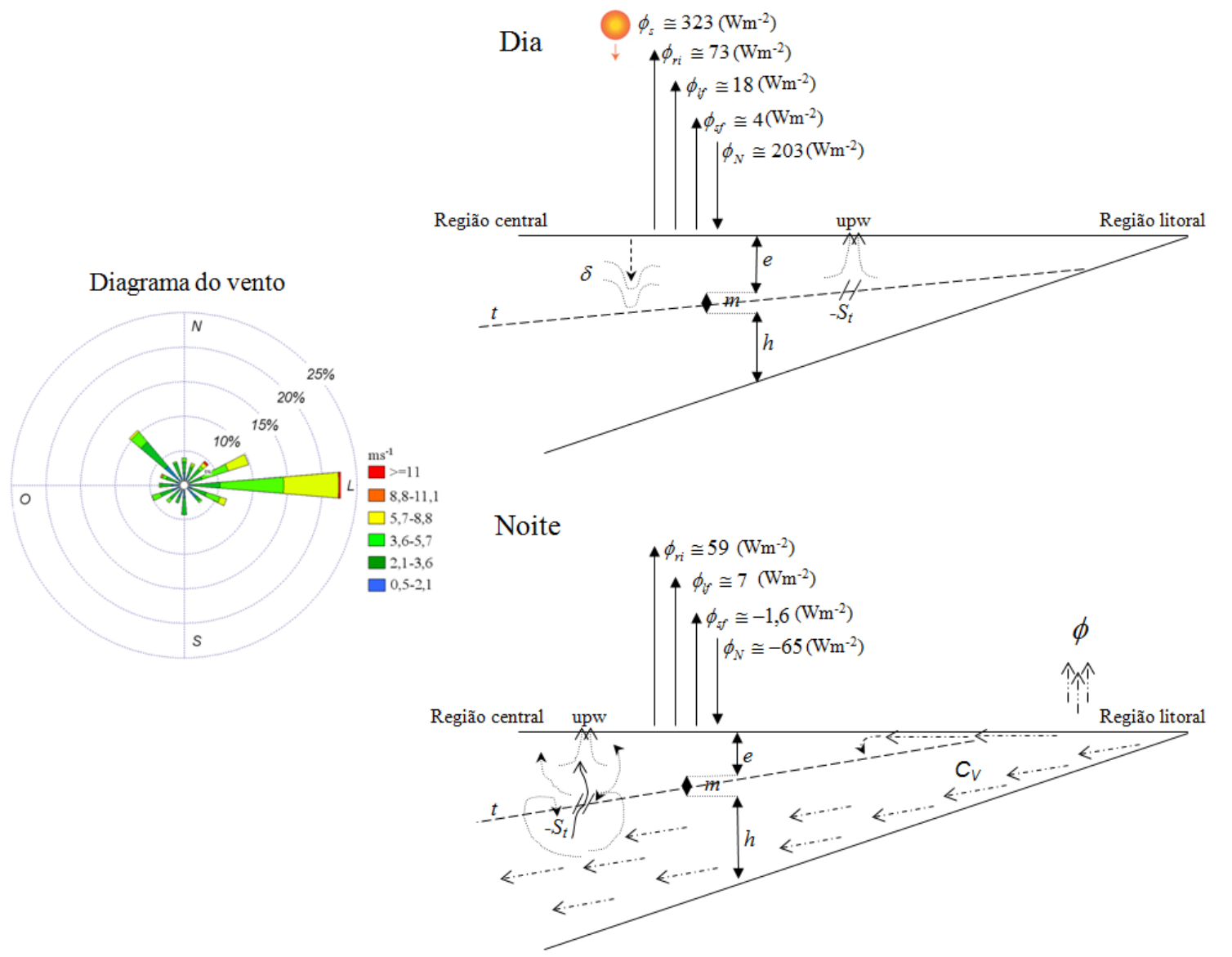

Figura 12. Modelo conceitual para o período de janeiro a maio (caso dia e noite). Em que: $\phi_{s}$ é a radiação de onda curta, $\phi_{r i}$ é a radiação de onda longa, $\phi_{l f}$ é o fluxo de calor latente, $\phi_{s f}$ é o fluxo de calor sensível, $\phi_{N}$ é o saldo de radiação, $E_{V}$ é a evaporação, e é o

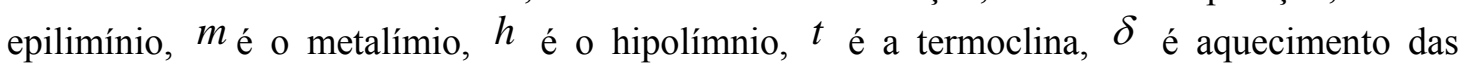
camadas adjacentes, $u p w$ é a ressurgência, $-S_{t}$ é a quebra da estabilidade da coluna d'água, $C_{V}$ é a transferência de água mais fria e densa da região rasa para a profunda e $\phi$ é a perda de calor nas regiões rasas durante a noite.

Já nos meses de junho e julho, a radiação de onda curta é baixa, com balanço de calor negativo, e evaporação próxima de $127\left(\mathrm{~mm} \mathrm{mês}^{-1}\right)$. Essa condição faz com o que ocorra um aumento dos processos de convecção turbulenta, fazendo com o que o pequeno gradiente de temperatura na coluna d'água seja diminuída ao máximo; fazendo com que a distribuição de temperatura na superfície torne-se homogênea. Esse período sofre influência da passagem de frentes frias.

Durante a noite, ocorre uma perda mais acentuada de radiação termal da superfície da água para a atmosfera, principalmente nas regiões rasas. Isso magnifica as correntes de densidade de profundidade, gerando ressurgências e afundamentos de massas d'água, principalmente devido à convecção turbulenta; permitindo a troca completa de massas d'água do hipolímnio para o epilímnio e do epilímnio para o hipolímnio. 


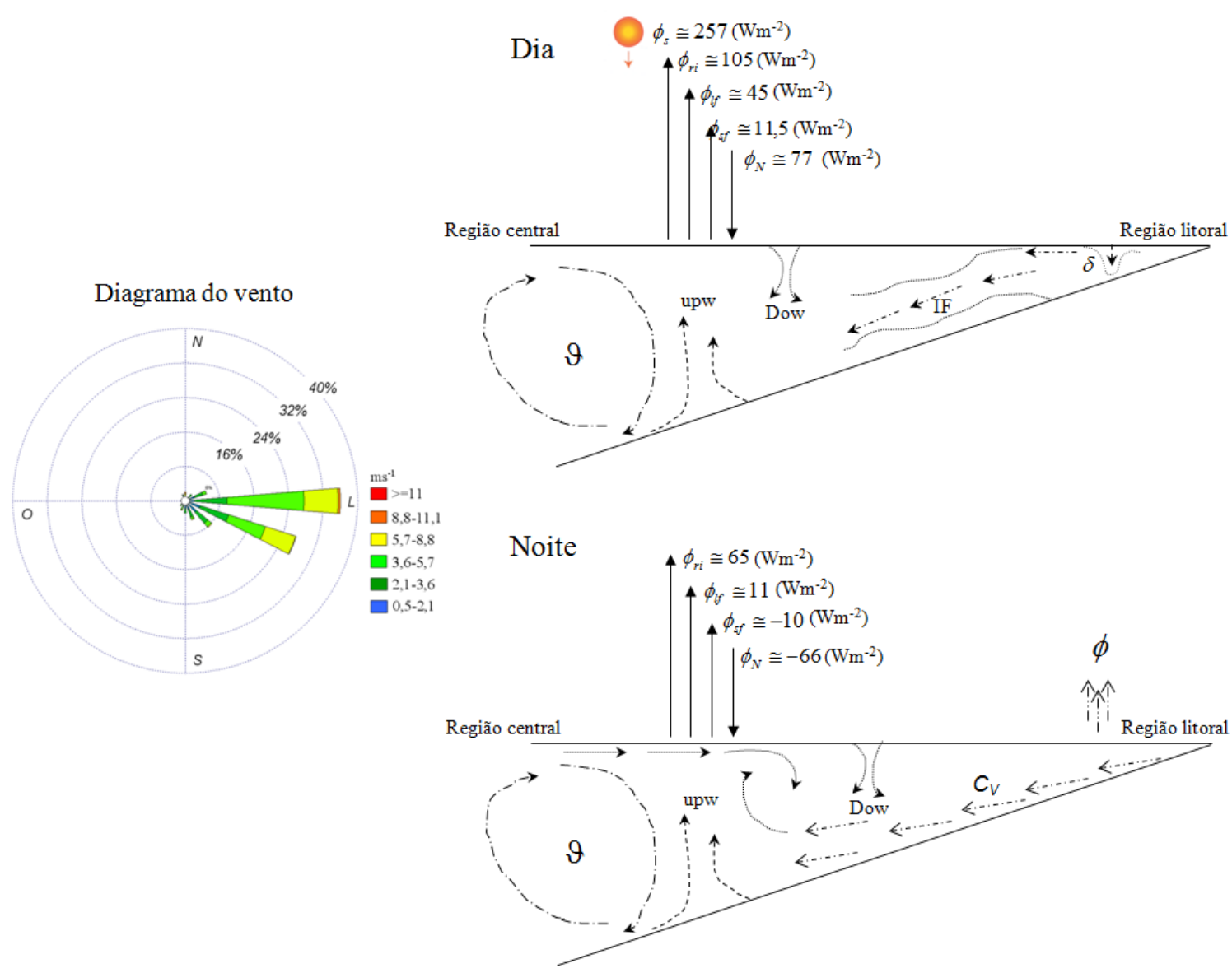

Figura 13. Modelo conceitual para o período de junho a setembro (caso dia e noite). Em que: $\phi_{s}$ é a radiação de onda curta, $\phi_{r i}$ é a radiação de onda longa, $\phi_{l f}$ é o fluxo de calor latente, $\phi_{s f}$ é o fluxo de calor sensível, $\phi_{N}$ é o saldo de radiação, $E_{V}$ é a evaporação, $\delta$ é aquecimento das mais rasas, IF é uma corrente de densidade intermediária (interflow) upw é a ressurgência, Dow é o afundamento de uma massa d'água, $\vartheta$ é a convecção turbulenta, $C_{V}$ é a transferência de água mais fria e densa da região rasa para a profunda e $\phi$ é a perda de calor nas regiões rasas durante a noite.

\subsubsection{De outubro a dezembro: retorno da estratificação}

Em outubro, a coluna d'água volta a estratificar-se com menor intensidade, e os processos observados durante os meses de janeiro a maio começam a atuar novamente (Figura 14). A grande diferença é que durante esse período de retorno da estratificação a ocorrência de ressurgência já não é mais provável, ou seja, a estabilidade da coluna d'água se torna mais forte. Outra diferença é que a termoclina tende a afundar (aumentando a camada do epilímnio) de outubro a dezembro, ao passo que de janeiro a maio a termoclina tende a subir. 
ALCÂNTARA, E. H. de; STECH, J. L. Desenvolvimento de modelo conceitual termodinâmico para o reservatório hidrelétrico de Itumbiara baseado em dados de satélite e telemétricos. Ambi-Agua, Taubaté, v. 6, n. 2, p. 157-179, 2011. (doi:10.4136/ambi-agua.192)

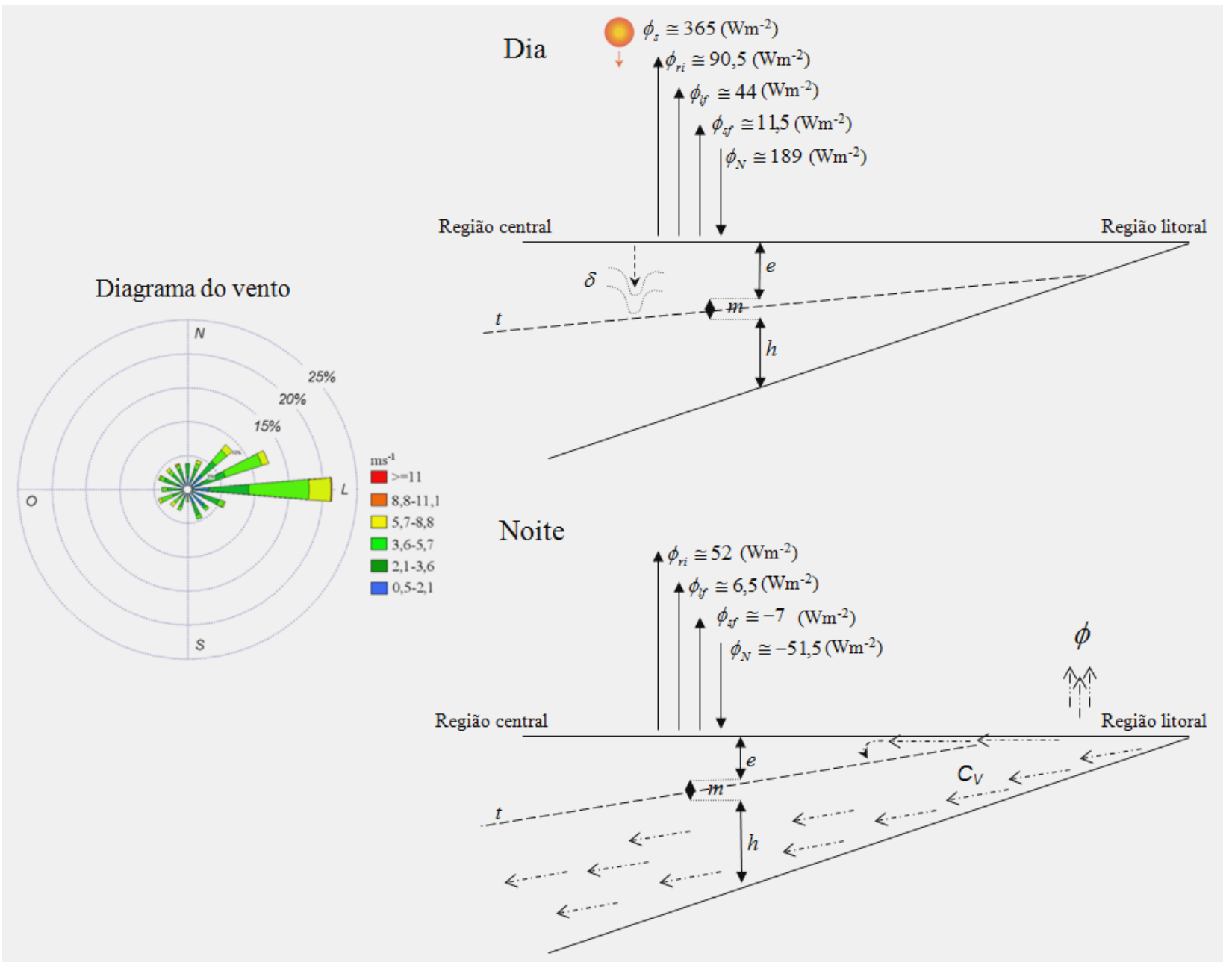

Figura 14. Modelo conceitual para o período de janeiro a maio (caso dia e noite). Em que: $\phi_{s}$ é a radiação de onda curta, $\phi_{r i}$ é a radiação de onda longa, $\phi_{l f}$ é o fluxo de calor latente, $\phi_{s f}$ é o fluxo de calor sensível, $\phi_{N}$ é o saldo de radiação, $E_{V}$ é a evaporação, e é o epilimínio, $m$ é o metalímio, $h$ é o hipolímnio, $t$ é a termoclina, $\delta$ é aquecimento das camadas adjacentes, $C_{V}$ é a transferência de água mais fria e densa da região rasa para a profunda e $\phi$ é a perda de calor nas regiões rasas durante a noite.

\section{CONCLUSÕES}

- Durante o dia a temperatura da água aquece do centro do reservatório para as margens;

- Durante a noite, o processo se inverte devido, principalmente, à convecção turbulenta causada pelo resfriamento diferencial;

- A temperatura para um dado fluxo de calor na superfície da água decresce ou aumenta rapidamente na região litoral devido à baixa profundidade;

- A análise sazonal mostrou que durante o verão, a temperatura da água é mais quente durante a noite do que de dia (perde calor mais lentamente);

- O reservatório ganha calor de janeiro a maio e de agosto a dezembro (alto potencial para estratificar);

- E perde de maio a agosto (alto potencial para misturar); 
ALCÂNTARA, E. H. de; STECH, J. L. Desenvolvimento de modelo conceitual termodinâmico para o reservatório hidrelétrico de Itumbiara baseado em dados de satélite e telemétricos. Ambi-Agua, Taubaté, v. 6, n. 2, p. 157-179, 2011. (doi:10.4136/ambi-agua.192)

- Apresenta diferença no balanço de calor na região próxima da barragem e dos rios (ponto de mergulho do rio);

- A temperatura da água durante a noite é mais complexa de modelar do que durante o dia por necessitar de mais parâmetros para explicar sua variação temporal e espacial.

\section{AGRADECIMENTOS}

Os autores agradecem ao projeto FAPESP n. 2007/08103-2 e INCT para Mudanças Climáticas, subprojeto Emissões de Lagos e Reservatórios (Processo FAPESP n. 08/57719-9) pelo auxílio financeiro. Os autores agradecem também FURNAS Centrais Elétricas pela cessão dos dados meteorológicos e de funcionamento do reservatório.

\section{REFERÊNCIAS}

ALCÂNTARA, E.; $\quad$ NOVO, E.; $\quad$ STECH, J.; $\quad$ LORENZZETTI, J.; $\quad$ BARBOSA, C.; ASSIREU, A. et al. A contribution to understanding the turbidity behaviour in an Amazon floodplain. Hydrology and Earth System Science, v. 14, p. 351-364, 2010a.

ALCÂNTARA, E. H.; STECH, J. L.; LORENZZETTI, J. A.; BONNET, M. P.; CASAMITJANA, X.; ASSIREU, A. T.; NOVO, E. M. Remote sensing of water surface temperature and heat flux over a tropical hydroelectric reservoir. Remote Sensing of Environment, v. 114, p. 2651-2665, 2010b.

AMBROSETTI, W.; BARBANTI, L.; SALA, N. Residence time and physical processes in lakes. Journal of Limnology, v. 63, p. 1-15, 2002.

ALSDORF, D. E.; LETTENMAIER, D. P. Tracking fresh water from space. Science, v. 301, p. 1491-1494, 2003. http://dx.doi.org/10.1126/science.1089802

BARBOSA, C. C. F.; NOVO, E. M. L. M.; MELACK, J. M.; FREITAS, R. M.; PEREIRA FILHO, W. Metodologia de análise da dinâmica de área e volume inundável: o exemplo da várzea do Lago Grande de Curuaí. Revista Brasileira de Cartografia, v. 58, p. 201$210,2006$.

BELETSKY, D.; SCHWAB, D. J. Modeling circulation and thermal structure in Lake Michigan: Annual cycle and interannual variability. Journal of Geophysical Research, v. 106, p. 19745-71, 2001. http://dx.doi.org/10.1029/2000JC000691

BUSSIERES, N.; VERSEGHY, D.; MACPHERSON, J. I. The evolution of AVHRR-derived water temperatures over boreal lakes, Remote Sensing of Environment, v. 80, p. 373384, 2002. http://dx.doi.org/10.1016/S0034-4257(01)00317-0

CASAMITJANA, X.; SERRA, T.; COLOMER, J.; BASERBA, C.; PÉREZ-LOSADA, J. Effects of the water withdrawal in the stratification patterns of a reservoir. Hydrobiologia, v. 504, p. 21-28, 2003.

http://dx.doi.org/10.1023/B:HYDR.0000008504.61773.77

CHAPRA, S. C.; RECKHOW, K. H. Engineering approaches for lake management. Vol. 2: mechanistic modeling. Boston: Butterworth Publishers. 1983. 492 p.

CHAPRA, S. C. Surface water-quality modeling. New York: McGraw-Hill, 1997. 
ALCÂNTARA, E. H. de; STECH, J. L. Desenvolvimento de modelo conceitual termodinâmico para o reservatório hidrelétrico de Itumbiara baseado em dados de satélite e telemétricos. Ambi-Agua, Taubaté, v. 6, n. 2, p. 157-179, 2011. (doi:10.4136/ambi-agua.192)

ESRI. ArcGIS 9: Using ArcGIS 3D analyst. ESRI Press. 2004, 390 p.

FORD, D. E. Reservoir transport process. In: THORTON, K. W.; KIMMEL, B. L.; PAYNE, F. E. (Eds.). Reservoir limnology: ecological perspectives. New York: John Wiley and Sons, 1990. p. 15-41.

HENDERSON-SELLERS, B. Calculating the surface energy balance for lake and reservoir modeling: a review. Reviews of Geophysics, v. 24, p. 625-649, 1986. http://dx.doi.org/10.1029/RG024i003p00625

HORNE, A. J.; GLODMAN, C. R. Limnology. New York: McGraw-Hill, 1994. 575 p.

IMBERGER, J. The diurnal mixed layer. Limnology and oceanography, v. 30, p. 737-770, 1985. http://dx.doi.org/10.4319/1o.1985.30.4.0737

ISAAKS, E. H.; SRIVASTAVA, M. R. An introduction to applied geostatistics. New York: Oxford University Press, 1989. 561 p.

KENNEDY, R. H. Reservoir design and operation: limnological implications and management opportunities. In: TUNDISI, J. G.; STRASKRABA, M. (Eds.). Theoretical reservoir ecology and its applications. Leiden: Backhuys Publishers, 1999. p. 1-28.

KIMMEL, B. L.; LIND, O. T.; PAULSON, L. J. Reservoir primary production. In: THORTON, K. W.; KIMMEL, B. L.; PAYNE, F. E. (Eds.). Reservoir limnology. New York: Ecological Perspectives; John Wiley and Sons, 1990. p. 133-194.

LERMAN, A.; IMBODEN, D. Physics and chemistry of lakes. 2. ed. New York: Springer, 1995.

LI, Z. L.; BECKER, F.; STOLL, M. P.; WAN, Z. Evaluation of six methods for extracting relative emissivity spectra from thermal infrared images. Remote Sensing of Environment, v. 69, p. 197-214, 1999. http://dx.doi.org/10.1016/S0034-4257(99)00049-8

LIVINGSTONE, D. Ice break-up on southern Lake Baikal and its relationship to local and regional air temperatures in Siberia and the North Atlantic Oscillation. Limnology and Oceanography, v. 44, p. 1486-1497, 1999.

http://dx.doi.org/10.4319/1o.1999.44.6.1486

LOFGREN, B.; ZHU, Y. Surface energy fluxes on the Great Lakes based on satelliteobserved surface temperatures 1992 to 1995. Journal of Great Lakes Research, v. 26, n. 3, p. 305-314., 2000. http://dx.doi.org/10.1016/S0380-1330(00)70694-0

MARTIN, J. L.; MCCUCHEON, S. C. Hydrodynamics and transport for water quality modeling. New York: Lewis Publishers, 1999.

MCFEETERS, S. K. The use of the Normalized Difference Water Index (NDWI) in the delineation of open water features. International Journal of Remote Sensing, v. 17, p. 1425-1432, 1996. http://dx.doi.org/10.1080/01431169608948714

MERWADE, V. Effect of spatial trends on interpolation of river bathymetry. Journal of Hydrology, v. 371, p. 169-181, 2009. http://dx.doi.org/10.1016/j.jhydrol.2009.03.026 
ALCÂNTARA, E. H. de; STECH, J. L. Desenvolvimento de modelo conceitual termodinâmico para o reservatório hidrelétrico de Itumbiara baseado em dados de satélite e telemétricos. Ambi-Agua, Taubaté, v. 6, n. 2, p. 157-179, 2011. (doi:10.4136/ambi-agua.192)

OESCH, D. C.; JAQUET, J. M.; HAUSER, A.; WUNDERLE, S. Lake surface water temperature retrieval using advanced very high resolution and Moderate Resolution Imaging Spectroradiometer data: Validation and feasibility study. J. Geophys. Res., v. 110, n. C12014, 2005.

REYNOLDS, R. W.; SMITH, T. M. Improved global sea surface temperature analyses using optimum interpolation. Journal of Climate, v. 7, p. 929-948, 1994. http://dx.doi.org/10.1175/1520-0442(1994)007<0929:IGSSTA>2.0.CO;2

ROBERTSON, D. M.; RAGOTZKIE, R. A. Changes in the thermal structure of moderate to large sized lakes in response to changes in air temperature. Aquatic Sciences, v. 52, p. 360-380, 1990. http://dx.doi.org/10.1007/BF00879763

RODRÍGUEZ-RODRÍGUEZ, M.; MORENO-OSTOS, E.; VICENTE, I.; CRUZ-PIZARRO, L.; SILVA, S. L. R. Thermal structure and energy budget in a small high mountain lake: La Caldera, Sierra Nevada, Spain. New Zealand Journal of Marine and Freshwater Research, v. 38, p. 879-894, 2004.

SCHOTT, J. R.; BARSI, J. A.; NORDGREN, B. L.; RAQUEÑO, N. G.; ALWIS, D. Calibration of Landsat thermal data and application to water resources studies. Remote Sensing of Environment, v. 78, p. 108-117, 2001. http://dx.doi.org/10.1016/S0034-4257(01)00253-X

STECH, J. L; LIMA, I. B. T.; NOVO, E. M. L. M.; SILVA, C. M.; ASSIREU, A. T.; LORENZZETTI, J. A. et al. Telemetric monitoring system for meteorological and limnological data acquisition. Verh. Internat. Verein Limnol., v. 29, p. 1747-1750, 2006.

STRAILE, D.; JÖHNK, K. D.; ROSSKNECHT, H. Complex effects of winter warming on the physico-chemical characteristics of a deep lake, Limnology and Oceanography, v. 48, p. 1432-1438, 2003. http://dx.doi.org/10.4319/1o.2003.48.4.1432

VOS, R. J.; HAKVOORT, J. H. M.; JORDANS, R. W. J.; IBELLINGS, B. W. Multiplatform optical monitoring of eutrophication in temporally and spatially variable lakes. The Science of the Total Environment, v. 312, n. 1/3, p. 221-243, 2003.

http://dx.doi.org/10.1016/S0048-9697(03)00225-0

WAN, Z.; ZHANG, Y.; ZHANG, Q.; LI, Z.-L. Quality assessment and validation of the global land surface temperature. International Journal of Remote Sensing, v. 25, p. 261-274, 2004. http://dx.doi.org/10.1080/0143116031000116417

WAN, Z. New refinements and validation of the MODIS land-surface temperature/emissivity products. Remote Sensing of Environment. v. 112, p. 59-74, 2008. http://dx.doi.org/10.1016/j.rse.2006.06.026

WETZEL, R. G.; LIKENS, G. E. Limnological Analysis. 3. ed. New York: Springer, 2000.

WETZEL, R. G. Limnology: lake and river ecosystems. 3. ed. San Diego: Academic Press, 2001.

WÜEST, A.; LORKE, A. Small-scale hydrodynamics in lakes. Annu. Rev. Fluid. Mech, v. 35, p. 373-412, 2003. 
ALCÂNTARA, E. H. de; STECH, J. L. Desenvolvimento de modelo conceitual termodinâmico para o reservatório hidrelétrico de Itumbiara baseado em dados de satélite e telemétricos. Ambi-Agua, Taubaté, v. 6, n. 2, p. 157-179, 2011. (doi:10.4136/ambi-agua.192)

ZAPADKA, T.; KRĘŹEL, A.; WOŹNIAK, B. Longwave radiation budget at the Baltic Sea surface from satellite and atmospheric model data. Oceanologia, v. 50, n. 2, p. 147-166, 2008. 